\title{
Re-evaluation of Spent Nuclear Fuel Assay Data for the Three Mile Island Unit 1 Reactor and Application to Code Validation*
}

\author{
I. C. Gauld, ${ }^{1)}$ J. M. Giaquinto, J. S. Delashmitt, J. Hu, G. Ilas, T. J. Haverlock, C. Romano
}

\author{
Oak Ridge National Laboratory \\ P.O. Box 2008 \\ Oak Ridge, TN 37831 \\ ${ }^{1)}$ Corresponding author: \\ I. C. Gauld \\ Oak Ridge National Laboratory \\ P.O. Box 2008 \\ Oak Ridge, TN 37831-6170 \\ Tel. $+1865-574-5257$ \\ Fax $+1865-574-9619$ \\ E-mail address:gauldi@ornl.gov
}

\footnotetext{
* This manuscript has been authored by UT-Battelle, LLC under Contract No. DE-AC05-00OR22725 with the U.S. Department of Energy. The United States Government retains and the publisher, by accepting the article for publication, acknowledges that the United States Government retains a non-exclusive, paid-up, irrevocable, world-wide license to publish or reproduce the published form of this manuscript, or allow others to do so, for United States Government purposes. The Department of Energy will provide public access to these results of federally sponsored research in accordance with the DOE Public Access Plan (http://energy.gov/downloads/doe-public-access-plan).
}

(C) 2015. This manuscript version is made available under the Elsevier user license http://www.elsevier.com/open-access/userlicense/1.0/ 


\begin{abstract}
Destructive radiochemical assay measurements of spent nuclear fuel rod segments from an assembly irradiated in the Three Mile Island unit 1 (TMI-1) pressurized water reactor have been performed at Oak Ridge National Laboratory (ORNL). Assay data are reported for five samples from two fuel rods of the same assembly. The TMI- 1 assembly was a $15 \times 15$ design with an initial enrichment of 4.013 wt $\%{ }^{235} \mathrm{U}$, and the measured samples achieved burnups between 45.5 and 54.5 gigawatt days per metric ton of initial uranium $(\mathrm{GWd} / \mathrm{t})$. Measurements were performed mainly using inductively coupled plasma mass spectrometry after elemental separation via high performance liquid chromatography. High precision measurements were achieved using isotope dilution techniques for many of the lanthanides, uranium, and plutonium isotopes. Measurements are reported for more than 50 different isotopes and 16 elements. One of the two TMI-1 fuel rods measured in this work had been measured previously by Argonne National Laboratory (ANL), and these data have been widely used to support code and nuclear data validation. The recent measurements performed by ORNL provided an important opportunity to independently cross check results against previous measurements performed at ANL. These measurements serve to improve confidence in the data, to verify reported uncertainties, and to investigate previous anomalies noted in the plutonium measurements. The measured nuclide concentrations are used to validate burnup calculations using the SCALE nuclear systems modeling and simulation code suite. These results show that the new measurements provide reliable benchmark data for computer code validation.
\end{abstract}

\title{
Keywords
}

Three Mile Island unit 1 reactor

Spent fuel radiochemical analysis

Inductively Coupled Plasma Mass Spectrometry with Isotopic Dilution

Isotopic assay benchmark data

SCALE nuclear systems modeling and simulation code 


\section{Introduction}

Measured isotopic concentrations from destructive assay of irradiated nuclear fuels provide the foundation for validating the computer codes and nuclear data libraries used in the design, safety, and licensing of spent nuclear fuel facilities. These isotopic concentrations also have important applications in spent fuel safeguards, non-proliferation, and other national nuclear security programs. The ability to benchmark computer code performance and quantify bias and uncertainty relies on the availability of accurate measurement data and a complete description of the fuel design and operating history information.

Measurements of spent fuel from the Three Mile Island unit 1 (TMI-1) reactor have been widely used as a source of validation data for computing codes and associated nuclear data [1,2]. Fuel samples from TMI-1 assembly NJ070G were previously measured at the radiochemical analysis laboratories at General Electric Vallecitos Nuclear Center (GE-VNC) [3], and samples from assembly NJ05YU were measured at Argonne National Laboratory (ANL) [4,5]. The measurements were performed under the Office of Civilian Radioactive Waste Management, Yucca Mountain Project, to support code validation for nuclear criticality safety analyses using burnup credit (crediting of changes in fuel composition and reduction in reactivity due to irradiation). The TMI-1 measurements, particularly those performed at ANL, are viewed as highly desirable because they provide extensive fission product measurements for many isotopes of importance to nuclear criticality safety using burnup credit data that are not available in most publicly available experimental programs. Without sufficient measurements to validate the calculated nuclide concentrations, these fission product nuclides cannot be used for safety evaluations.

However, experience with some of the NJ05YU assay data measured by ANL has been problematic due to very large discrepancies observed between measured and predicted plutonium concentrations in all samples [1,2]. The differences are larger than what can be explained on the basis of laboratory-estimated bias and uncertainty, or uncertainties associated with the reactor operating conditions [6]. The measured $\mathrm{Pu}$ data were also inconsistent with experimental data obtained from other fuels with similar properties [2,7]. A potentially important aspect of the history of assemblies NJ070G and NJ05YU is that they both operated in cycle 10 of the TMI-1 reactor, when significant operating anomalies occurred that resulted in fuel failures. A root cause analysis of cycle 10 anomalies was performed by the Electric Power Research Institute (EPRI) [8,9].

The impact of uncertainties due to the operational anomalies on the isotopic depletion is judged to be very minor, and analysis of the related operating data uncertainties has not resolved the discrepancies [6]. Assembly NJ05YU rod H6, measured by ANL, experienced some deposits of 
crud; however, this rod was located at the interior of the assembly, well away from the periphery rods that experienced more severe effects. The measurements performed at GE-VNC on assembly NJ070G were made on corner and edge rods (O1, O11, O12, O13) that experienced cladding degradation, and one rod (O11) failed. Unlike the ANL measurement data for assembly NJ05YU, data for assembly NJ070G measured at GE-VNC show no similar deviations, and the results are generally very consistent with predictions and other experimental data [2,7]. The agreement between measurements and prediction for the NJ070G rods affirms that the operating anomalies during cycle 10 did not likely play a significant role in the isotopic depletion. To date there has been no strong technical basis or experimental evidence to support rejection of the ANL data for use in code validation. However, the consequences of using the data for code validation are large discrepancies between measurements and predictions, and correspondingly, large margins of safety for calculation uncertainty.

Under an experimental project carried out in 2013 for the US Department of Energy (DOE), Office of Defense Nuclear Non-proliferation R\&D, new destructive analysis measurements of spent fuel samples from TMI-1 assembly NJ05YU were performed at Oak Ridge National Laboratory (ORNL). These measurements were designed to provide experimental correlations between nondestructive assay (NDA) gamma measurements acquired using a high purity germanium (HPGe) detector and the nuclide content of the fuel obtained from destructive analysis of the same fuel segments. Results from the NDA analysis have been previously reported [10].

This paper focuses on evaluation of the destructive assay data acquired under the ORNL experimental project. Along with providing additional benchmark data for validation, these new assay data provide an important, unique opportunity to re-evaluate earlier destructive analysis measurements performed by ANL on TMI-1 fuel rod H6. The measurements performed at ORNL used higher precision mass spectrometry techniques than those used previously. In addition, they provided two additional samples obtained from rod H6 and three new samples from fuel rod D5 from the same NJ05YU assembly. Independent laboratory cross-check measurements performed on rod H6 fuel samples were used to re-evaluate the measurement results, identify potentially incompatible data, and confirm the uncertainty estimates provided by the laboratories, thereby improving the quality of the data for the purposes of benchmarking computer code predictions. Resolving the long-standing anomalies in the plutonium data is an important objective for the data evaluation.

\section{Description of the TMI-1 fuel}


Measurements performed at ORNL were made on two fuel rods from assembly NJ05YU, a Babcock and Wilcox Mark-B8 $15 \times 15$ lattice design. This assembly operated for two consecutive cycles, cycle 9 and 10, and achieved an average burnup of 48.6 gigawatt days per metric ton of initial uranium $(\mathrm{GWd} / \mathrm{t})$. The measured fuel rods, identified as rods $\mathrm{H} 6$ and D5, had an initial enrichment of $4.013 \mathrm{wt} \%{ }^{235} \mathrm{U}$ and achieved nominal rod burnups of 48.7 and $49.4 \mathrm{GWd} / \mathrm{t}$, respectively. The location of the measured fuel rods in the assembly is illustrated in Fig. 1. Lattice positions that do not contain fuel rods, including guide tubes (GT) and the central instrument tube (IT), are also shown.

Design data for assembly NJ05YU are summarized in Table 1. The TMI-1 reactor operating history data for cycles 9 and 10 are summarized in Table 2. The assembly contained $16 \mathrm{Al}_{2} \mathrm{O}_{3}-\mathrm{B}_{4} \mathrm{C}$ burnable poison rods located in the GT locations during cycle 9. These absorber rods were withdrawn after cycle 9. The presence of these rods during irradiation has a significant impact on the neutron spectrum of the assembly and therefore the cross sections that influence isotopic transmutation of the fuel, particularly in fuel rods located in close proximity to the absorber rods. These rods act by displacing the water moderator in the guide tubes and by introducing a strong thermal neutron absorber (boron).

Isotopic measurements at ANL were performed on fuel rod H6. This rod was identified using the ANL Alpha Gamma Hot Cell Facility identifier of AG536. A total of 11 samples were measured at ANL from rod H6 in two experimental phases; Phase 1 was performed in September 1998 and Phase 2 in May 2000. Several fuel segments from assembly NJ05YU were shipped to ORNL in 2008, including segments from rod H6 and from a second rod D5 (AG616). The ORNL isotopic measurements were performed on two samples from rod H6 and three samples from rod D5 in 2013.

The axial locations (elevation from bottom of fuel rod) of the two samples from rod H6 that were measured at ORNL were selected from rod locations adjacent to samples measured previously at ANL; therefore, they provide an independent assessment of the nuclide content and uncertainties. The axial locations of the fuel samples measured at both laboratories are listed in Table 3 and are illustrated in Fig. 2 with the assembly grid spacer locations shown. The indicated burnup for each sample is the value as determined experimentally by the respective laboratories based on the measured ${ }^{148} \mathrm{Nd}$ content.

There are two cross-check samples from rod H6 (AG536): (1) ANL sample C2B and ORNL sample C2D1, and (2) ANL sample C1 and ORNL sample C2D2. Samples from rod D5 (AG616) were selected from two rod sections (A and B) cut from different rod elevations to obtain a wider range of burnup values. The section identifiers for rod D5, where A corresponds to the top section 
of the fuel rod, were reversed from the sample identifiers for rod H6 used at ANL, where section A refers to the bottom section of the fuel rod.

One ORNL sample, B2, was located in close proximity to a grid spacer location and was selected specifically to assess the potential impact of grid spacers on nuclide compositions. The roughly 5-cm high grid spacers act to locally depress the thermal neutron flux by displacing the water moderator, thereby also altering the neutron spectrum. Therefore, it is important to identify samples in close proximity to grid spacers since additional information is required to accurately model these regions.

\section{Experimental}

\subsection{Measured isotopes}

The measurements performed by ORNL included 14 actinides and 36 fission products. Highprecision mass spectrometry with isotopic dilution measurements were performed for the isotopes of uranium, plutonium, neodymium, samarium, europium, gadolinium, cesium, and cerium. The measured isotopes are widely included in modern experimental programs [11-13] because of their importance to a broad range of nuclear applications including criticality safety for spent fuel using burnup credit, radiological consequence analysis, neutron and gamma radiation sources, and nuclear decay heat. Uncertainties for these measurements were typically less than $2 \%$ for the major isotopic species at the $95 \%$ confidence level (2-sigma). Mass spectrometry with external calibration was used to measure ${ }^{109} \mathrm{Ag},{ }^{95} \mathrm{Mo},{ }^{103} \mathrm{Rh},{ }^{99} \mathrm{Tc},{ }^{237} \mathrm{~Np},{ }^{243} \mathrm{Am}$, and ${ }^{244} \mathrm{Cm}$, with a $95 \%$ uncertainty of about $10 \%$. Gamma spectrometry of the dissolver solution was used to measure ${ }^{241} \mathrm{Am},{ }^{134} \mathrm{Cs},{ }^{137} \mathrm{Cs},{ }^{154} \mathrm{Eu}$ and ${ }^{155} \mathrm{Eu}$ - also with an uncertainty of about $10 \%$. Compared to the measurements performed by ANL [5], the new measurements include higher precision destructive analysis data for additional isotopes of cesium $\left({ }^{133} \mathrm{Cs},{ }^{134} \mathrm{Cs}\right.$, and $\left.{ }^{135} \mathrm{Cs}\right)$ that were not previously available. The nuclides ${ }^{134} \mathrm{Cs}$ and ${ }^{135} \mathrm{Cs}$ are of high importance to decay heat and long-term waste management, respectively [14], and ${ }^{133} \mathrm{Cs}$ is widely considered in burnup credit analyses for spent fuel transportation packages and storage facilities [15].

\subsection{Fuel rod gamma scans}

High resolution axial gamma scans were performed on fuel rod sections from rods H6 (AG536) and D5 (AG616) at the ORNL Irradiated Fuel Examination Facility. The three sections were identified in cutting diagrams as rod AG536 section C2D, rod AG616 section A, and rod AG616 
section B. These sections were approximately 38, 74, and $69 \mathrm{~cm}(15,29$, and 27 in) long, respectively. Fig. 3-5 show the axial gamma scans for fuel rod sections AG536 C2D, AG616 A, and AG616 B.

The ${ }^{137}$ Cs gamma scans were used primarily to ensure no anomalies in the burnup distribution in the vicinity of the samples, confirm the orientation of the measured segments after shipping, identify grid spacer locations, and locate fuel pellet interfaces for purposes of sample cutting.

The fuel samples cut for destructive analysis were about $11 \mathrm{~mm}$ in length $(0.43 \mathrm{in})$, representing approximately one fuel pellet. The cuts were performed near the pellet center to avoid cutting at the pellet interfaces. This procedure ensured that a sufficient amount of fuel material was available for representative measurements; it also minimized the potential for biased results caused by nonuniform nuclide distributions which could occur in the fuel due to burnup and temperature gradients that can cause migration of certain volatile species.

Gamma measurements of the fuel rod segments involving extended counting time were also performed at the axial locations corresponding to the samples used for destructive analysis. Although not within the scope of the present work, these measurements were performed to provide experimental correlations between destructive assay data and HPGe gamma measurements for the purposes of improving the interpretation of spent fuel NDA measurements.

\subsection{Dissolution methods}

Dissolution of the five spent fuel segments for destructive analyses were performed within a shielded hot cell cubicle using a closed digestion rig specifically designed for high-precision recovery and quantification of the elements and isotopes analyzed. The rig's closed design also served to protect the samples from external sources of legacy radiological contamination within the cubicle. The dissolution apparatus consisted of a borosilicate glass pressure bottle to which a water cooled condenser was mated via a Teflon compression fitting. The condenser allowed for refluxing of the dissolver solution for the entire heating period. To transfer the final digest from the pressure bottle and into a dilution bottle, the condenser was removed, and a threaded Teflon spout was put in its place which allowed for drip-free pouring. A separate digestion rig was used for each of the TMI fuel specimens analyzed. The fuel digestion rig and condenser is shown in Fig. 6.

For each of the digestions, the following sample preparation protocol was used. First, the combined weight of the fuel-clad segment was measured. The entire specimen was then transferred into the pressure bottle, and approximately $150 \mathrm{~mL}$ of $12 \mathrm{M}$ ultra-pure nitric acid ("Optima," Fisher Scientific) was added to the vessel. The bottle was then mated to the condenser, and chill water flow 
was established and maintained at $10{ }^{\circ} \mathrm{C}$ for the entire heating period. The chill water was supplied by a solid-state ultra-compact thermoelectric recirculating chiller (Oasis 190, Solid State Cooling Systems, Wappingers Falls, NY) which has proven to be very reliable and able to withstand the extremely high dose rates present in the cell bank. The digestion apparatus was stabilized directly onto a laboratory hotplate which was heated to surface temperatures between 170 to $180{ }^{\circ} \mathrm{C}$ (solution temperature was $\sim 150{ }^{\circ} \mathrm{C}$ ). The heating period was maintained for 40 to 50 hours. The long heating period was required to allow for complete dissolution of the fuel specimens, excluding the trace concentrations of refractory metals. It is common practice to use small volumes of hydrofluoric acid (HF) to speed the dissolution of the metal oxides in the fuel; however, ORNL's nuclear facility where the work was performed restricts the use of HF in the hot cell cubicles. At the completion of the dissolution, the digest was cooled, the condenser was removed, and a threaded Teflon spout was attached. The digested fuel, intact cladding segment, and any undissolved metallic particulates were rinsed through a $0.45 \mu \mathrm{m}$ cellulose acetate filter into a pre-weighed dilution bottle using a vacuum draw. After a thorough rinse, the cladding segment was removed, allowed to dry in a desiccator, and then weighed. The weight of the fuel was calculated as the difference between the initial total fuel-clad weight and the post-digestion cladding weight.

The filtered dissolver solution was diluted gravimetrically to its final weight using ultra-pure 12 M nitric acid. This solution was designated as the master analytical solution (MAS). A portion of the MAS was removed from the hot cell cubicle and transferred to a glove box laboratory. In the glove box, a $0.2 \mathrm{~mL}$ sub-aliquot of the MAS was gravimetrically added to a second container with a pre-weighed amount of ultra-pure $8 \mathrm{M}$ nitric acid. This solution was designated as the working solution (WS). It was from these solutions that all aliquots for each detailed destructive analysis were taken.

Analysis of the undissolved solids (UDS) from the fuel digestions was not performed for these TMI-1 samples. However, experience from past spent fuel digestions involving similar irradiated $\mathrm{UO}_{2}$ and mixed oxide (MOX) fuels, as well as the detailed analysis of the UDS metallic elements, yielded minimal elemental concentrations in the solids. Typical values were less than $0.001 \%$ of that predicted for the elements Mo, Tc, Ru, Rh, Ag, and Pd [16].

All weights obtained as part of the gravimetric dissolution protocol and follow-on isotope dilution mass spectrometry (IDMS) measurements were an average of three replicates. Fuel specimen weights, as well as MAS and WS solution weights, are listed in Table 4. The five fuel specimens were numbered as TMI 1-5 for the internal laboratory analysis work. The corresponding fuel sample identifiers giving the fuel rod and sample ID are also shown in Table 4. 


\subsection{Gamma spectrometry}

Gamma spectrometry measurements were performed using a Canberra Genie-2000 Data Acquisition System in conjunction with high-purity Ge detectors and Canberra Lynx modules used for the measurements and data reduction. The system was calibrated using QCY48 mixed gamma nuclide standards traceable to the National Institute of Standards and Technology (NIST). Daily calibration verification was performed using secondary NIST-traceable standards.

For the gamma spectrometry measurements, digested spent fuel aliquots were diluted using nitric acid to reduce the count rate with $<10 \%$ dead time. The estimated relative 2 -sigma uncertainty of the measurements was $10 \%$ based on historical measurements of gamma control samples. Gamma spectrometry was used to measure ${ }^{241} \mathrm{Am},{ }^{134} \mathrm{Cs},{ }^{137} \mathrm{Cs},{ }^{154} \mathrm{Eu}$, and ${ }^{155} \mathrm{Eu}$. With the exception of ${ }^{241} \mathrm{Am}$, radiochemical analysis of these nuclides was also performed by IDMS, and the gamma spectrometry results serve as an independent cross-check of the mass spectrometry results.

\subsection{Alpha spectrometry}

Alpha spectrometry was used to monitor the activities of ${ }^{238} \mathrm{Pu},{ }^{239} \mathrm{Pu},{ }^{240} \mathrm{Pu},{ }^{241} \mathrm{Am},{ }^{243} \mathrm{Am},{ }^{243} \mathrm{Cm}$ and ${ }^{244} \mathrm{Cm}$ during processing. Although these results were not used to determine the concentrations of these actinides, alpha monitoring was a key element in the internal evaluation of data quality.

For alpha spectrometry, aliquots were diluted using nitric acid to obtain a satisfactory gross count rate $(<150,000$ counts per minute) and to keep the amount of solids on a plate to a minimum. The diluted aliquots were evaporated on a $3.8-\mathrm{cm}$ diameter stainless steel plate using a laboratory hotplate. Once dried, plates were then flamed to dull red with a Meker burner. The total solids on these counting plates are considered essentially weightless, so the counting results are not corrected for any mass absorption due to solids content. The plates were counted using a Protean MPC 2000 single open-window gas flow proportional counter. Counting efficiencies for gross alpha activity measurements are based on essentially weightless NIST-traceable ${ }^{244} \mathrm{Cm}$ standards. Counting efficiencies were confirmed daily using secondary NIST traceable standards. After gross alpha measurement, the plates were analyzed for discrete alpha energies using a Canberra Genie-2000 Data Acquisition System and passivated implanted planar silicon (PIPS) detectors. The alpha spectrometry analyses were used to determine the emitted alpha energy ratios. These analyses were conducted in conjunction with the respective gross alpha analysis to associate alpha activity to the detected alpha energies. Based on historical measurements of alpha control samples, a relative 2sigma total uncertainty of $10 \%$ is assigned to the alpha spectrometry results. 


\subsection{Radiochemical analysis}

\subsubsection{Measurements by ICPMS external calibration}

Selected actinide and fission product isotopes were measured using inductively coupled plasma mass spectrometry (ICPMS) with external calibrations. External calibration curves for each of the measured fission product isotopes were made using NIST-traceable certified standards. Natural isotopic abundances were used to calculate specific isotopic concentrations in the calibration solutions. Calibration verifications were performed using NIST-traceable standards prepared from independent lots. External calibrations for the actinide isotopes were generated using a NISTtraceable commercial uranium standard and New Brunswick Laboratory (NBL) plutonium

CRM137. The ${ }^{238} \mathrm{U}$ and ${ }^{239} \mathrm{Pu}$ responses were used to generate a "semi-quantitative" response curve for the high mass region to quantify the other measured actinide isotopes. Independent lots of uranium and plutonium standards were used for calibration verifications. Based on historical measurements of ICPMS control samples a relative 2-sigma uncertainty of $10 \%$ was assigned to the results.

\subsubsection{Measurements by high performance liquid chromatography (HPLC) separations and IDMS}

Selected actinide and fission product isotopes were measured using IDMS techniques. The enriched lanthanide standards were obtained through the DOE National Isotope Development Center (NIDC) located at ORNL. Elemental assays used for the analyses were based on measured weights of the oxide standards, and gravimetric dilutions were confirmed by reverse IDMS using NIST single-element standards and high precision multi-collector ICPMS (MC-ICPMS). The ${ }^{242} \mathrm{Pu}-$ enriched standard used was prepared from a legacy plutonium metal coupon, isotopically measured by high-precision MC-ICPMS, and verified for elemental assay by reverse IDMS (MC-ICPMS) using IRMM-082, ${ }^{239} \mathrm{Pu}$ spike, nitrate solution. The enriched uranium standard used was CRM $111 \mathrm{~A}$ purchased from NBL. For Cs, a NIST traceable natural ${ }^{133} \mathrm{Cs}$ standard obtained from a commercial vendor was used. A list of the isotopically enriched sources used for isotopic dilution spiking standards is shown in Table 5.

Each of the sample aliquots measured using the IDMS technique was purified for the element being quantified prior to the mass spectrometry isotope ratio measurements. This was accomplished using HPLC for all fission-product spiked and unspiked aliquots, as well as plutonium unspiked aliquots. Separations for uranium isotopics were not performed since uranium makes up the bulk of the spent fuel matrix with no significant isobaric interferences. For the HPLC separations, a Dionex 
DX600 ion chromatograph and AS-DV auto sampler equipped with a $100 \mu \mathrm{L}$ sample loop and 10port injections switching valve was used.

For separations of the lanthanide elements and removal of the bulk uranium matrix, the Dionex system was equipped with an IonPac CS-10 analytical column $(250 \times 4 \mathrm{~mm}$ ID). The HPLC process involved loading the samples onto the analytical column in high nitric acid. Next, complexation of the uranium using dilute hydrochloric acid removed the bulk of the fuel matrix to waste. Lastly, the retained trace lanthanide elements were selectively eluted off of the column by chelation chromatography using a dilute solution of 2-hydroxyisobutyric acid (HIBA). This analytical methodology effectively isolates purified fractions of each lanthanide element from the high uranium matrix of the dissolver solution to allow for high-accuracy isotopic measurements using mass spectrometry. The purified fractions were collected off-line and then measured for their respective elemental isotopic abundances using quadrupole ICPMS.

For Cs separations, the Dionex system was equipped with an IonPac CS-16 analytical column $(250 \times 4 \mathrm{~mm}$ ID). The HPLC separation process involved loading the samples onto the analytical column in high nitric acid, followed by elution of the cesium selectively from the uranium matrix and other fission products using a dilute eluent of methanesulfonic acid (MSA). This analytical methodology effectively isolates purified fractions of cesium from the high uranium matrix and barium isobaric interference to allow for high-accuracy isotopic measurements using mass spectrometry. The purified Cs fractions were collected off-line and then measured for isotopic abundances using quadrupole ICPMS.

For plutonium isotopic distributions in the unspiked samples, the Dionex system was equipped with an IonPac CS-10 analytical column $(250 \times 4 \mathrm{~mm}$ ID). Since the TMI-1 specimens had been through a very aggressive high-molarity nitric acid digestion protocol, the majority of the Pu species was present as $\mathrm{Pu}^{+4}$, which is the oxidation state desired for the separation chemistry. However, prior to the HPLC separations, valence adjustment of the Pu species was performed to convert all $\mathrm{Pu}$ species to the +4 valence state. Valence adjustment of the samples was accomplished by addition of a small amount of $30 \%$ hydrogen peroxide and gentle heating (<80 C). HPLC separations were accomplished using a dilute nitric acid eluent with which the $\mathrm{Pu}$ is eluted prior to $\mathrm{U}$ using the CS10 analytical column. After collection of the purified plutonium fraction the $U$ and Am were stripped and directed to waste using a dilute $\mathrm{HCl}$ eluent.

Equilibrated and spiked aliquots of samples investigated for Pu by IDMS measurements were purified using an anion exchange (AEX) separation process. The spiked mixtures were loaded in high nitric acid onto $2 \mathrm{~mL}$ conditioned DOWEX MP-1 AEX resin columns (converted to nitrate 
form). After generous high nitric acid rinses to remove uranium, the plutonium was stripped from the column using low molarity nitric acid.

For uranium, the only isobaric interference for the isotopic measurement would be from the

${ }^{238} \mathrm{Pu}$ content of the spent fuel. The amount of ${ }^{238} \mathrm{Pu}$, however, is insignificant compared to the bulk

${ }^{238} \mathrm{U}$ present. Therefore, a separation for $\mathrm{U}$ isotopics was not required. Instead, the dissolved fuel specimens (spiked and unspiked aliquots) were measured directly using mass spectrometry after the appropriate dilutions.

Each separation described above (lanthanides, $\mathrm{Cs}$, and $\mathrm{Pu}$ ) consisted of a batch of four samples: the unspiked specimen, the equilibrated spiked specimen, an acid blank, and a control sample.

\subsection{Measurement results and uncertainties}

The measurement results in units of $\mathrm{mg} / \mathrm{g} \mathrm{U}$ (initial) for the five samples measured at ORNL are listed in Table 6, along with the measurement method, measurement date, and estimated uncertainty. All uncertainty values are given at the 95\% (2-sigma) confidence level. The absolute mass concentrations were normalized using the measured fuel sample weights (Table 4). Nuclide masses in Table 6 that were measured by gamma spectroscopy were obtained by converting the measured activities to mass using half-life values from ENDF/B-VII.1 [17]. No additional uncertainty was assigned to the final mass due to the unit conversion.

A global check on the measured concentrations was first performed using a mass balance calculation that compares the heavy metal mass of the fuel sample prior to dissolution obtained by weighing, with the measured heavy metal mass after irradiation corrected for losses due to fission. The number of fissions was obtained from the measured values of percent fission per initial heavy metal atom (\%FIMA) in Table 3. For all samples, the mass balance deviation was typically $1 \%$ or less with the exception of sample AG536 C2D1 (1.6\%). These deviations are consistent with the reported measurement uncertainties for the major $U$ isotopes of about $1 \%$ and are consistent with deviations typically seen in other experimental programs [12].

Evaluations of the combined standard uncertainties (CSUs) for IDMS results were performed using the GUM Workbench software, version 2.4 (Metrodata, GmBH) [18]. The GUM Workbench is based on the ISO/IEC document Guide to the Expression of Uncertainty in Measurement [19] and provides a systematic approach to capture the uncertainties associated with each step of an analytical methodology.

\subsection{Burnup analysis}


The burnup for each TMI-1 sample was determined experimentally using the guidance established in the ASTM E 321-96 Standard Test Method for Atom Percent Fission in Uranium and Plutonium Fuel (Neodymium-148 Method) [20]. The overall effective fractional fission yield for

${ }^{148} \mathrm{Nd}$ was estimated to be $1.706 \%$ using the weighted average of the percent thermal fissions from ${ }^{235} \mathrm{U},{ }^{239} \mathrm{Pu},{ }^{241} \mathrm{Pu}$, and fast fission from ${ }^{238} \mathrm{U}$ per the guidance in the standard method. The estimated burnup values were further verified using burnup calculations that reproduced the measured ${ }^{148} \mathrm{Nd}$ concentrations. These code-based burnup values were well within $1 \%$ of values estimated using ASTM E 321-96 standard method using the approximate conversion factor of $9.6 \mathrm{GWd} / \mathrm{t}$ per \%FIMA [20]. Burnup is listed in Table 3 in units of both the \%FIMA and GWd/t.

Evaluations of CSUs for the ${ }^{148} \mathrm{Nd}$ results were performed using the GUM Workbench. From these evaluations, it was estimated that the ${ }^{148} \mathrm{Nd}$ burnup values have a relative 2 -sigma uncertainty of $3.0 \%$.

\section{Computational Analysis}

\subsection{Codes and nuclear data}

The SCALE nuclear modeling and simulation code system [21,22], version 6.1.2, was used to calculate the isotopic composition of the five TMI-1 spent fuel samples measured by ORNL. SCALE is used internationally for nuclear systems design and safety analyses, including nuclear criticality safety, shielding, and spent nuclear fuel studies. The depletion and decay calculations in SCALE are performed by the Oak Ridge Isotope Generation (ORIGEN) code [23] that has been extensively validated using measured assay data for more than 150 samples from commercial light water reactors $[24,25]$.

Fuel burnup calculations require accurate cross sections to simulate isotopic transmutation of the fuel during irradiation. Within SCALE, time-dependent cross sections may be calculated using onedimensional neutron transport $\left(X S D R N S_{N}\right.$ code), two-dimensional transport $\left(N E W T S_{N}\right.$ code), or three-dimensional transport (KENO Monte Carlo code). The transport code may be selected by the user depending on the geometric complexity of the problem to be solved. SCALE couples the neutron transport analysis for the fuel assembly model with the ORIGEN code that calculates the time-dependent nuclide compositions during irradiation and decay, and it generates radiological properties of the fuel such as decay heat and the neutron and gamma ray emission rates and energy spectra. The depletion calculation is performed within an automated SCALE sequence called TRITON, which performs data handling and execution of all the codes required for the complete time-dependent analysis. 
Nuclear data used in the calculations can have a large impact on the accuracy of computed results [7]. In this study, the 238-energy-group cross-section library based on ENDF/B-VII.0 data [26] was used for the neutron transport calculation (fuel assembly model). Cross sections for each material in the library, approximately 450 nuclides, and all reaction channels are collapsed using the neutron flux solution from the transport calculation and are applied to determine the reaction rates in the ORIGEN calculation. Cross sections for nuclides not available in ENDF/B-VII.0 are obtained from the JEFF-3.0/A special purpose activation library that contains data for 774 materials and more than 12,000 neutron-induced reactions [27].

Resonance processing of the ENDF/B-VII.0 cross section data, which is required for multigroup transport methods, is performed using the CENTRM code in SCALE. This code provides a continuous-energy transport solution over the resonance energy range using a cell model of the fuel and moderator. The flux solution from CENTRM is then used to collapse point-wise cross sections into self-shielded problem-dependent multigroup data.

The nuclear decay data used by ORIGEN are based entirely on the evaluations from ENDF/BVII.1 [17].

\subsection{Assembly model and design data}

Geometry and material data used to model assembly NJ05YU are listed in Table 1. A twodimensional transport model of the assembly was developed for the NEWT $\mathrm{S}_{\mathrm{N}}$ transport code. This model effectively represented a cross section of the assembly at the elevation of the measured sample. The axial variation of the assembly operating conditions at the different sample heights is treated using separate models for each sample; each sample model uses the local reactor conditions, such as moderator temperature, density, and power. Several samples were located relatively close to grid spacers. However, details of the grid spacer design were not available, so a more detailed threedimensional model was not possible. The assembly model is illustrated in Fig. 7. The measured fuel rod and its nearest neighbors are depleted individually to accurately represent the local neutronic environment of the measured rod. The other fuel rods in the assembly are depleted as a single fuel material for efficiency using the average neutron cross sections computed for these rods. Reflective assembly boundary conditions were applied, effectively representing an infinite array of the assemblies. This approach has been shown to produce results that are comparable to models that explicitly account for the neighboring assemblies [14]. Fuel rods located at the inner region of the assembly in particular exhibit very low impact from the neutronic influence of the neighbor assemblies. All fuel rods in the assembly model were depleted independently in the burnup analysis. 


\subsection{Reactor operating history data}

Assembly NJ05YU operated in TMI-1 during cycles 9 and 10. The reactor cycle start and end dates and effective full power days are summarized in Table 2. Additional time-dependent operating history data are required to develop an accurate benchmark model, including:

- soluble boron concentration in the coolant,

- local power level in the measured sample,

- water moderator temperature and density at the elevation of the sample, and

- fuel temperature.

These parameters are time-dependent, and with the exception of the measured boron content in the water, they are usually determined by the reactor operator using reactor simulation codes that incorporate in-core instrument monitoring data. Reactor operating data were available for fuel rods D5 and H6 of assembly NJ05YU in 18 discrete axial zones (nodes) [1,28]. The nodal data were used to estimate the local operating conditions at the axial elevation of each sample. These data are provided at irradiation time intervals of nominally 70 days, corresponding to burnup steps of about $3 \mathrm{GWd} / \mathrm{t}$ or less. The time-dependent variations of the soluble boron content, water moderator density, specific power, and fuel temperature during irradiation were represented in the model using the same temporal fidelity as provided in the operating data. While cycle-averaged data may be accurate for many operating parameters, such as the soluble boron content [13], a detailed representation of the parameter time variations was included in the benchmark models to minimize any bias due to modeling approximations.

The water moderator conditions during cycles 9 and 10 are given in Table 7, including the timedependent boron concentration and the water density at the elevation of each measured sample. The specific power and fuel temperatures are listed in Table 8. The specific power values are obtained by adjusting the node power provided by the operator to obtain the local sample burnup as determined experimentally from the ${ }^{148} \mathrm{Nd}$ measurements.

Separate assembly models were developed to represent the change in the assembly configuration due to removal of 16 burnable poison rods from the guide tube locations between cycles 9 and 10 . To model this configuration change, the fuel compositions at the end of the cycle 9 depletion simulation were extracted and used as input data in a second model corresponding to cycle 10 (with no burnable absorber rods present). A total of 232 nuclides representing the light elements, actinides, and fission products was used to represent the irradiation fuel compositions for each rod in the assembly at the start of cycle 10 . 


\section{Results and discussion}

The calculated results for each of the five samples are compared to measurements in Table 9 as the ratio of the calculated-to-experimental $(\mathrm{C} / \mathrm{E})$ nuclide concentrations. For the purposes of the comparison, the measured nuclide contents in Table 6 were decay adjusted to a common reference date of July 9, 2013. This date corresponds to the Sm measurements, which cannot be adjusted for decay without the promethium decay precursors (e.g., ${ }^{147} \mathrm{Pm} \rightarrow{ }^{147} \mathrm{Sm}$ ) which were not measured. All measurements were made within $\sim 150$ days of the reference date, resulting in relatively small decay adjustments for most nuclides.

The burnup of each sample was adjusted in the calculations to closely reproduce the measured ${ }^{148} \mathrm{Nd}$ concentration. These adjusted burnup values, listed in Table 9 , are well within $1 \%$ of the burnup values in Table 3 determined by the laboratory using the ASTM method. The adjustments are therefore within the estimated $3 \%$ uncertainty in the laboratory burnup values.

The D5 rod sample AG616 B2 was specifically selected at the location of an assembly grid spacer. The impact of the spacer on the nuclide concentrations (e.g., ${ }^{235} \mathrm{U}$ and ${ }^{239} \mathrm{Pu}$ ) is evident. For example, ${ }^{239} \mathrm{Pu}$ is underpredicted in the spacer grid sample by almost $8 \%$ relative to the average of the other four samples, and ${ }^{235} \mathrm{U}$ is underestimated by more than $6 \%$. These results indicate that while grid spacers decrease the local burnup, they increase production of ${ }^{239} \mathrm{Pu}$ compared to other locations of the fuel rod. These deviations are consistent with local flux spectrum changes in the vicinity of the spacer grid (not included in the simulations) and are caused mostly by displacement of the water moderator that in turn leads to locally increased ${ }^{238} \mathrm{U}$ capture and Pu production.

Table 9 includes the average $\mathrm{C} / \mathrm{E}$ value and the relative standard deviation of four samples (excluding grid spacer sample AG616 B2). The calculated results are generally in good agreement with measurements for most nuclides and are consistent with the results of previous validation studies performed using SCALE and ENDF/B-VII cross sections based on analysis of 92 spent fuel samples [7]. The relative standard deviation (RSD) of the C/E values can be compared to the laboratory measurement uncertainties listed in Table 9. Although the RSD values include contributions from computational uncertainties, the comparison provides a qualitative assessment and shows that the estimated uncertainties are generally consistent with the observed variation in the results of the different samples.

\subsection{Gamma spectrometry measurements}

The gamma spectrometry data for ${ }^{134} \mathrm{Cs},{ }^{137} \mathrm{Cs},{ }^{154} \mathrm{Eu}$ and ${ }^{155} \mathrm{Eu}$ - obtained on the dissolved solutions - were used primarily to verify the mass spectrometry results available for these isotopes. 
In most cases the results from the different measurement techniques were compatible, and the mass spectrometry results were therefore used as the reference measurement data with much lower measurement uncertainties. The exception was ${ }^{134} \mathrm{Cs}$, which generally exhibited poor agreement between gamma and mass spectrometry results. This can be attributed to the large measurement uncertainties in the mass spectrometry result for this isotope of $20-32 \%$, which were caused by the very low atomic abundance of this isotope in elemental Cs $(0.02 \%)$ for the measured samples. The measurement accuracy of the mass spectrometry method for low abundance isotopes is investigated further later in the paper. In this work, the gamma spectroscopy results for ${ }^{134} \mathrm{Cs}$ were used as the reference data with an estimated relative measurement uncertainty (2-sigma) of $10 \%$.

\subsection{Mass spectrometry measurements}

The uranium isotopes are generally predicted within $5 \%$ of the measurements. On average, ${ }^{235} \mathrm{U}$ is underpredicted by the code by $5.2 \%$, and ${ }^{238} \mathrm{U}$ is underpredicted by $1.2 \%$. The ${ }^{235} \mathrm{U}$ concentration at the end of irradiation is very sensitive to the sample burnup as estimated from measurements. For the burnup of the TMI-1 samples, a $2 \%$ relative error in the burnup estimate will result in a 7\% error in the calculated ${ }^{235} \mathrm{U}$ concentration. Although ${ }^{148} \mathrm{Nd}$ was used as the basis for the sample burnup estimates in this study, the calculated concentrations of stable or long-lived isotopes ${ }^{133} \mathrm{Cs},{ }^{137} \mathrm{Cs}$, ${ }^{140} \mathrm{Ce}$, and ${ }^{142} \mathrm{Ce}$, are overpredicted by $4-5 \%$, suggesting a possible overestimate of the burnup value used in the calculations. The observed ${ }^{235} \mathrm{U}$ deviations are well within the range expected based on the likely burnup uncertainty. The ${ }^{233} \mathrm{U}$ is significantly underpredicted at only $\sim 1-2 \%$ of the measured concentrations. It is unclear if this is a result of measurement uncertainty, estimated at $100 \%$, due to the very low isotopic abundance of ${ }^{233} \mathrm{U}\left(<10^{-6}\right)$ or to the calculations.

The average ${ }^{238} \mathrm{U}$ bias is larger than previous experience has shown, but it is consistent with the estimated measurement uncertainty. This bias was also observed in the mass balance check and is consistent with measured $\mathrm{U}$ concentrations that are likely overestimated. The major $\mathrm{Pu}$ isotopes are predicted on average within 3-5\%; these results are very consistent with previous experience using ENDF/B-VII.0 nuclear data [7].

Neodymium isotopes are predicted within $4 \%$ of measurement. Both ${ }^{143} \mathrm{Nd}$ and ${ }^{145} \mathrm{Nd}$ are important burnup credit nuclides. Samarium isotopes are within $9 \%$ of measurements, with ${ }^{149} \mathrm{Sm}$, a key burnup credit fission product, predicted within 3\%. Again, the results are highly consistent with previous experience. The ${ }^{149} \mathrm{Sm}$ and ${ }^{151} \mathrm{Sm}$ isotopes are present at very low isotopic concentrations in spent fuel, making them more difficult to measure by ICPMS; their measurement uncertainties are correspondingly much larger than for other Sm isotopes. The Eu isotopes are within $12 \%$ of 
measurement with the exception of ${ }^{152} \mathrm{Eu}$, which occurs at extremely low concentrations and exhibits erratic behavior likely attributed to measurement problems. The Gd isotopes are predicted within $\sim 10 \%$, with the exception of the very low concentration isotopes ${ }^{152} \mathrm{Gd}$ and ${ }^{157} \mathrm{Gd}$, and ${ }^{158} \mathrm{Gd}$, which exhibit an average calculational bias of $20 \%$.

The $\mathrm{Cs}$ and $\mathrm{Ce}$ isotopes are in consistent agreement with measurements, with all values measured by IDMS being within about $5 \%$ with the exception of the ${ }^{134} \mathrm{Cs}$ result (13\%), which is measured using lower precision gamma spectrometry with an estimated relative uncertainty of $\pm 10 \%$.

The measured metallic species associated with UDS, ${ }^{95} \mathrm{Mo}$ and ${ }^{109} \mathrm{Ag}$, are predicted within the measurement uncertainty of $\pm 10 \%$. The results for ${ }^{99} \mathrm{Tc}$ and ${ }^{103} \mathrm{Rh}$ are underpredicted on average by $18 \%$ and $13 \%$, respectively. The agreement confirms that the dissolution procedure (without separate analysis for UDS) was adequate to capture the metallic nuclides in solution (e.g., a loss of material to UDS would appear as a large positive calculation bias).

The Am isotopes agree within the measurement uncertainty of $\pm 11 \%$. However, ${ }^{237} \mathrm{~Np}$ and ${ }^{244} \mathrm{Cm}$ are underpredicted by up to $20 \%$. These results are outside the range of past experience [7], where validation studies indicated an average within $\sim 3 \%$, although there is a significant variation between the results of different experimental programs.

In general, the estimated measurement uncertainties are consistent with the observed RSD in the $\mathrm{C} / \mathrm{E}$ comparisons from Table 9. However, this is not the case for nuclides with very low relative isotopic concentrations. For example, the isotopes ${ }^{152} \mathrm{Eu}$ and ${ }^{152} \mathrm{Gd}$ occur at isotopic fractions of $0.14 \%$ and $0.06 \%$, respectively, and they have estimated measurement uncertainties up to $16 \%$. However, evaluation of the data indicates RSD variations of more than 50\%. A global analysis of the uncertainties is illustrated in Fig. 8, showing the observed RSD of the five samples as a function of the relative atom fraction for each isotope measured by ID-ICPMS. The error bars represent the measurement uncertainties estimated by the laboratory. The figure indicates that most isotopes with relative isotopic fractions greater than about $4 \times 10^{-3}$ exhibit variations that are consistent with the estimated measurement uncertainties. However, at lower isotopic concentrations, the precision of the method clearly deteriorates, and alternate higher-precision measurement techniques may be required.

\subsection{Analysis of cross-check samples}

Two samples from fuel rod H6 measured by ORNL (AG536 C2D1 and C2D2) were obtained from the same rod and at adjacent axial locations as the two samples measured previously by ANL 
(AG536 C1 and C2B1). These measurements provided an opportunity to independently cross check the measurement data and verify uncertainties as reported by the different laboratories. The ANL measurement results were decay corrected to the reference date of the ORNL measurements for the purpose of the comparisons.

The ANL and ORNL laboratory measurements were compared against the calculated nuclide compositions of the fuel. The calculations used in the comparisons are based on sample burnups as determined from the ORNL-measured ${ }^{148} \mathrm{Nd}$ concentration. The measurements performed at ANL did not use isotopic dilution for the fission products, and this resulted in relatively large uncertainties in the ${ }^{148} \mathrm{Nd}$ burnup estimates of $\pm 14 \%$, and for ${ }^{137} \mathrm{Cs} \pm 10 \%$. Uncertainty in the burnup has a direct effect on uncertainties in the calculations, and it affects all nuclides differently. The component of uncertainty associated with the burnup estimates was not considered in the error bars shown on the plots in this section. However, the effect would be to increase the error above the levels shown, particularly in the case of the ANL data, due to the large measurement uncertainties.

The same calculated concentrations were used in the comparisons since the duplicate samples where obtained from adjacent axial locations of the same rod, so the nuclide concentrations are expected to be very similar. These comparisons directly reflect differences in the measurements while also showing the relative agreement with calculations.

\subsubsection{Uranium and plutonium}

A comparison of the ORNL and ANL results for the $\mathrm{U}$ and Pu isotopes for the two duplicate samples from rod H6 are shown in Fig. 9 as the C/E ratio of the nuclide compositions. Error bars represent the reported 2-sigma measurement uncertainties. The $\mathrm{U}$ results are in good agreement and are well within the measurement uncertainties. The Pu concentrations measured by ANL for both samples are approximately 15-25\% lower than the values measured by ORNL (indicating greater apparent overestimation of calculated Pu using the ANL values in the figure). The results indicate a significant bias between the two laboratory measurements.

Large deviations between calculated and measured $\mathrm{Pu}$ concentrations have been previously documented [1,2] for the TMI-1 fuel rod H6 samples, and computational benchmark results for these samples are inconsistent with benchmark data evaluated from more than 90 other fuel samples [7]. A cause for the anomalies has not been identified. The current work using higher precision measurements provides strong experimental evidence that the anomalies are likely attributed to large bias in the ANL measurements. When the measurement uncertainties are considered, results for rod AG536 sample C2D1 are largely compatible at the 95\% confidence level (i.e., the error bars 
generally overlap); however, the isotopes of ${ }^{239} \mathrm{Pu}$ and ${ }^{240} \mathrm{Pu}$ for sample C2D2 are incompatible. The large uncertainties in the ANL measurements (>10\% for the Pu isotopes) greatly limit the value of the data for code validation.

\subsubsection{Lanthanide fission products}

The cross-check analysis was extended to include the fission products measured by IDMS including isotopes of $\mathrm{Nd}, \mathrm{Sm}, \mathrm{Eu}$, and Gd. Fig. 10 shows the results for the $\mathrm{Nd}$ and $\mathrm{Sm}$ isotopes that were measured by ORNL, along with the isotopes measured by ANL, while Fig. 11 shows the results for Eu and $\mathrm{Gd}$ isotopes. The ANL measurements were limited to ${ }^{143} \mathrm{Nd},{ }^{145} \mathrm{Nd},{ }^{148} \mathrm{Nd},{ }^{147} \mathrm{Sm}$, ${ }^{149} \mathrm{Sm},{ }^{150} \mathrm{Sm},{ }^{151} \mathrm{Sm},{ }^{151} \mathrm{Eu},{ }^{153} \mathrm{Eu},{ }^{155} \mathrm{Eu}$, and ${ }^{155} \mathrm{Gd}$. In general there is poor agreement between the laboratory measurement results for these nuclides. However, as seen in the actinide results, the data are compatible for many isotopes when the 2-sigma measurement uncertainties are considered.

The calculations are typically within $\sim 5 \%$ of the ORNL measurements for the $\mathrm{Nd}$ and $\mathrm{Sm}$ isotopes. These results are consistent with previous benchmark experience. The ANL results exhibit much larger deviations and in general are biased by about $10 \%$ (lower measured concentrations). The calculated results for the Eu and Gd isotopes are generally in good agreement with the ORNL measurements, within about $5 \%$, with the exception of the low abundance ${ }^{152} \mathrm{Gd}$ and ${ }^{157} \mathrm{Gd}$ isotopes discussed previously. The ANL and ORNL measurement results for the Eu and Gd isotopes are largely incompatible.

Consistency of the Eu and Gd results was checked by comparing the bias observed between ${ }^{155} \mathrm{Eu}$ and its decay daughter ${ }^{155} \mathrm{Gd}$. At the time of measurement, effectively all the ${ }^{155} \mathrm{Gd}$ is produced from decay of ${ }^{155} \mathrm{Eu}$, and the computational bias observed in these parent-daughter nuclides should be equal. The ORNL measurements are compatible within the 2-sigma measurement uncertainties of less than 2.5\%. The ANL results are in good agreement for rod AG536 sample C2D2 but exhibit significant deviations of $\sim 30 \%$ in sample C2D1, indicating measurement problems. Again, the large ANL measurement uncertainties of more than $10 \%$ make these comparisons problematic.

\subsubsection{Metallic fission products and minor actinides}

The results for the metallic fission products $\left({ }^{95} \mathrm{Mo},{ }^{99} \mathrm{Tc},{ }^{103} \mathrm{Rh},{ }^{109} \mathrm{Ag}\right)$ and minor actinides $\left({ }^{237} \mathrm{~Np},{ }^{241} \mathrm{Am},{ }^{243} \mathrm{Am}\right.$, and $\left.{ }^{244} \mathrm{Cm}\right)$ measured by ICPMS with external calibration, are shown in Fig. 12, providing cross-check data for all nuclides except ${ }^{244} \mathrm{Cm}$ which was not measured at ANL. The metallic nuclides frequently exhibit large measurement variability due to their association with UDS during the fuel dissolution process and the instability of ${ }^{109} \mathrm{Ag}$ in solution. Unlike most of the other 
nuclides, the metallic fission products were analyzed at ANL and ORNL using similar techniques and have comparable measurement uncertainties of about $10 \%$. The agreement between the laboratories is typically poor, with most results being incompatible at the $95 \%$ confidence level, with the exception of ${ }^{99} \mathrm{Tc}$. The nuclide contents measured by ORNL are typically lower than those measured by ANL by about $20 \%$ on average. The deviation of the ${ }^{109} \mathrm{Ag}$ result measured by ANL is likely attributed to difficulties in measurements associated with instability of $\mathrm{Ag}$ and incomplete recovery in solution.

The results for ${ }^{241} \mathrm{Am}$ are also incompatible. At the time of the measurements, most of the ${ }^{241} \mathrm{Am}$ would be generated as a decay daughter of ${ }^{241} \mathrm{Pu}$. Consequently, the calculated bias observed in ${ }^{241} \mathrm{Am}$ should be very similar to that of ${ }^{241} \mathrm{Pu}$. The actual deviations are observed to be larger: however, the measurement uncertainties at both laboratories contribute to significant uncertainty in evaluating the results.

\section{Conclusions}

The importance of having access to high quality assay data for validation of computer models used to calculate spent fuel nuclide compositions is widely recognized. International activities related to spent nuclear fuel are increasing as many countries are considering expanded use of dry cask storage. In addition, Sweden and Finland are rapidly nearing completion of their final spent fuel repositories. The design, performance, safety, and licensing of spent fuel facilities rely on accurate computational methods to assess the nuclide contents and radiological characteristics. These methods and nuclear data must be underpinned by experimental data used for code validation to determine computational bias and uncertainty.

The measurements performed by ORNL represent an important contribution to benchmark data for validating codes, providing higher precision measurements for more isotopes important to spent fuel studies than were previously available for TMI-1 fuel. In addition to the destructive analysis measurements described in this work, gamma measurements using HPGe detectors have been made on the fuel rod segments prior to radiochemical analysis. These measurements provide experimental data to support the interpretation of spent fuel NDA measurements used in safeguards. These measurements have been evaluated and reported previously [10].

The new radiochemical assay measurements also provide direct experimental evidence that earlier measurements performed on assembly NJ05YU rod H6 fuel by ANL are likely biased for many nuclides. The new measurements indicate that the anomalies previously observed in the plutonium isotopes are likely attributed to the measurements. This assessment is made on the basis 
of comparisons of the ANL measurements relative to the new higher precision measurements at ORNL and the agreement of the new measurements with the results for other similar fuels.

The measurements performed by ANL did not make extensive use of the isotopic dilution technique in the mass spectrometry measurements, leading to relatively large uncertainties for many nuclides. For example, ${ }^{148} \mathrm{Nd}$ and ${ }^{137} \mathrm{Cs}$, key burnup indicators, have measurement uncertainties exceeding $10 \%$, and consequently the sample burnup cannot be determined better than this value. The large uncertainty in the burnup, a value required as input to the computer code spent fuel model being validated, may result in added calculation error in many other nuclides. These results indicate that the use of ICPMS must be used in combination with isotopic dilution (spiking) techniques for calibration in order to achieve the high measurement precision required for code validation.

This study also highlights the importance and need for independent laboratory radiochemical analyses of spent fuel samples to confirm accuracy of the measurements. Since there are no reference standards of spent nuclear fuel material, laboratory cross-check analyses represent an important experimental program element to identify potential measurement problems and confirm the uncertainty estimates. Independent measurements should always include all phases of the analytical process, including fuel dissolution, separations, standards, spiking, radiochemical analysis, and data reduction. Independent measurements, while increasing experimental costs, have been widely used in earlier European programs [29] and are a key element of modern experimental programs [11-13].

One limitation observed in the ICPMS instrument used in the ORNL work is the difficulty in obtaining high precision results for nuclides at low isotopic concentrations, and for several of these nuclides, the uncertainties estimated using the GUM Workbench appear to be underestimated. This issue will be investigated for future work on spent fuels performed by ORNL's nuclear analytical group. Increasing the accuracy and precision for these low-abundance isotopes would likely require alternate thermal ionization mass spectrometry (TIMS) or multi-collector ICPMS (MC-ICPMS) instruments. However, for the large majority of nuclides the measurement precision achieved using ICPMS with isotopic dilution is observed to be very good, with predicted and observed variability (1 sigma) that is generally $2 \%$ or lower.

The code validation results obtained with SCALE using the new ORNL measurements appear to be very consistent with previous experience for similar fuels, confirming the accuracy of the data and its suitability for code benchmarking. These measurements provide valuable benchmark data for an expanded set of nuclides important to nuclear criticality safety, decay heat, and neutron and gamma ray source terms used in many spent fuel safety applications. The TMI-1 measurement data and associated design and operating history data are currently being added to a new public database 
of spent fuel nuclide compositions, SFCOMPO, under an activity coordinated by the Organization for Economic Cooperation and Development (OECD), Nuclear Energy Agency (NEA). The OECD/NEA Expert Group on Assay Data for Spent Nuclear Fuel [13] is engaged in compiling benchmark assay data for criticality safety and other scientific activities related to the nuclear fuel cycle, nuclear facility safety, and waste management. Practitioners in the areas of spent fuel composition and source term analysis in industry, research, and regulatory organizations should be aware of these activities and the measurement data that are available to support code validation for a broad range of potential spent nuclear fuel applications.

\section{Acknowledgements}

This work was supported by the U.S. Department of Energy, Office of Defense Nuclear Nonproliferation R\&D (NA-22) and Office of Nonproliferation and Arms Control (NA-24) under contract No. DE-AC05-00OR22725. Acquisition of the spent fuel rod sections from ANL that were used in this work was coordinated under previous activities of the Office of Civilian Radioactive Waste Management, Yucca Mountain Project.

\section{References}

[1] J. M. Scaglione, Three Mile Island Unit 1 Radiochemical Assay Comparisons to SAS2H Calculations, Yucca Mountain Project Report, CAL-UDC-NU-000011, Revision A, April 2002.

[2] G. Ilas, I. C. Gauld, F. C. Difilippo, and M. B. Emmett, Analysis of Experimental Data for High Burnup PWR Spent Fuel Isotopic Validation - Calvert Cliffs, Takahama, and Three Mile Island Reactors, U. S. Nuclear Regulatory Commission, NUREG/CR-6968 (ORNL/TM2008/071), 2010.

[3] R. D. Reager and R. B. Adamson, TRW Yucca Mountain Project, Test Report, GE Nuclear Energy, Phase 2, Ref. TRW Purchase Order No. A09112CC8A, 2000.

[4] S. F. Wolf, D. L. Bowers, and J. C. Cunnane, Analysis of Spent Nuclear Fuel Samples from Three Mile Island and Quad Cities Reactors: Final Report, Argonne National Laboratory, November 2000.

[5] S. F. Wolf, D. L. Bowers, J. C. Cunnane, J. Radioanal. Nucl. Chem., 263, No. 3 (2005) 581586.

[6] B. E. Mays, C. W. Mays, and J. J. Sapyta, Trans. Am. Nucl. Soc., 106, Chicago Il., June 2428 (2012) 836-838.

[7] G. Ilas, I. C. Gauld, and G. Radulescu, Ann. Nucl. Energy 46 (2012) 43-55. 
[8] TMI-1 Cycle 10 Fuel Rod Failures, Volume 1: Root Cause Failure Evaluations, Electric Power Research Institute, EPRI Report TR-108784-V1, 1998.

[9] TMI-1 Cycle 10 Fuel Rod Failures, Volume 2: Hot Cell Examinations, Electric Power Research Institute, EPRI Report TR-108784-V2, 1998.

[10] S. Richards and C. E. Romano, Determination of Plutonium Content in Spent Fuel from Passive Gamma Measurements, American Nuclear Society, in: CD Proceedings of the 9th International Conference on Facility Operations - Safeguards Interface, 2012.

[11] D. Boulanger, et al., High burnup PWR and BWR MOX fuel performance: a review of Belgonucleaire recent experimental programs, in: CD Proceedings of the 2004 International Meeting on LWR Fuel Performance, 2014.

[12] R. T. Primm, ARIANE International Programme - Final Report, Oak Ridge National Laboratory, ORNL/SUB/97-XSV750-1, May 1, 2003.

[13] H. U. Zwicky, J. Low, M. Granfors, et al., J. Nucl. Mater. 402 (2010) 60-73.

[14] Spent Nuclear Fuel Assay Data for Isotopic Validation, Nuclear Energy Agency (NEA), NEA/NSC/WPNCS/DOC(2011)5, OECD/NEA, Paris (2011).

[15] Proceedings of the IAEA Technical Meeting on Advances in Applications of Burnup Credit to Enhance Spent Fuel Transportation, Storage, Reprocessing and Disposition, IAEATECDOC-1547, ISBN 92-0-103307-9, 2005.

[16] J. S. Delashmitt, R. D. Canaan, J. M. Giaquinto, R. R. Smith, and B. K. Woody, High Precision Hot Cell Dissolution Protocol for Irradiated Mixed Oxide Fuels, Institute of Nuclear Materials Management, in: 52 ${ }^{\text {nd }}$ Annual Meeting Proceedings, 2011.

[17] M. B. Chadwick, M. Herman, P. Obložinský, et al., Nucl. Data Sheets, 112 (2011) 28872996.

[18] GUM Workbench Professional Version 2.4, Metrodata GmbH, Grenzach-Wyhlen, Germany.

[19] Uncertainty of Measurement - Part 3: Guide to the Expression of Uncertainty in Measurement (GUM:1995), ISO/IEC Guide 98-3:2008, 2008.

[20] Standard test method for atom percent fission in uranium and plutonium fuel (Neodymium148 Method). Annual Book of ASTM Standards, 12.02(E321-79), p. 91, 1995.

[21] S. M. Bowman, Nucl. Technol. 174(2) (2011) 126-148.

[22] SCALE: A Comprehensive Modeling and Simulation Suite for Nuclear Safety Analysis and Design, ORNL/TM-2005/39, Version 6.1, Oak Ridge National Laboratory, Oak Ridge, Tennessee, June 2011. Available from Radiation Safety Information Computational Center at Oak Ridge National Laboratory as CCC-785. 
[23] I. C. Gauld, G. Radulescu, G. Ilas, B. D. Murphy, M. L. Williams, and D. Wiarda, Nucl. Technol. 174(2) (2011) 169-195.

[24] G. Radulescu, I. C. Gauld, G. llas, J. C. Wagner, Nucl. Technol. 188(2) (2014) 154-157.

[25] U. Mertyurek, M. W. Francis, I. C. Gauld, SCALE 5 Analysis of BWR Spent Nuclear Fuel Isotopic Compositions for Safety Studies, Oak Ridge National Laboratory, ORNL/TM2010/286, 2010.

[26] M. B. Chadwick, P. Obložinský, M. Herman et al., Nucl. Data Sheets, 107 (2006) 2931-3060.

[27] J-Ch Sublet, A. J. Koning, R. A. Forrest and J. Kopecky, The JEFF-3.0/A Neutron Activation File-EAF-2003 into ENDF-6 Format, Commissariat à l'Energie Atomique, France, JEFDOC-982, November 2003.

[28] L. B. Wimmer, Summary Report of Commercial Reactor Criticality Data for Three Mile Island Unit 1, Bechtel SAIC Company, TDR-UDC-NU-000004 Revision 01, 2001.

[29] S. Guardini and G. Guzzi, Benchmark Reference Data on Post Irradiation Analysis of Light Water Reactor Fuel Samples, Commission of the European Communities, Nuclear Science and Technology, Joint Research Center, Report EUR 7879 EN, 1983. 


\section{List of Figure legends}

1. Fuel rod layout of TMI-1 assembly NJ05YU showing measured fuel rods, guide tubes, and central instrument tube locations

2. Grid spacer and cutting locations for fuel samples obtained from rods AG536 (H6) and AG616 (D5)

3. Axial ${ }^{137} \mathrm{Cs}$ gamma scan of fuel rod H6 segment AG536 C2D showing locations of samples C2D1 and C2D2 used for destructive analysis

4. Axial ${ }^{137}$ Cs gamma scan of fuel rod D5 section AG616A showing location of sample A1 used for destructive analysis

5. Axial ${ }^{137}$ Cs gamma scan of fuel rod D5 segment AG616B in vicinity of measured samples showing location of samples B1 and B2

6. Hot cell fuel digestion and condenser rig

7. Model of assembly NJ05YU developed for the analysis of fuel rod H6 (green fuel rod), showing burnable poison rods (yellow) present in cycle 9

8. The observed relative standard deviation (RSD) in the nuclide $\mathrm{C} / \mathrm{E}$ values as a function of the relative isotope atom fraction (in the element). The error bars show the 1-sigma measurement uncertainty as estimated by the laboratory

9. Comparison of calculated and measured $\mathrm{U}$ and $\mathrm{Pu}$ nuclide contents for duplicate samples measured at ORNL and ANL for rod segment AG536

10. Comparison of calculated and measured lanthanide fission product $(\mathrm{Nd}, \mathrm{Sm})$ nuclide contents for duplicate samples measured at ORNL and ANL for rod segment AG536

11. Comparison of calculated and measured lanthanide fission products $(\mathrm{Eu}, \mathrm{Gd})$ nuclide contents for duplicate samples measured at ORNL and ANL for rod segment AG536

12. Comparison of calculated and measured metallic fission products and minor actinides for duplicate samples measured at ORNL and ANL 


\section{List of Tables}

1. Design specifications for TMI-1 assembly NJ05YU

2. TMI-1 reactor operating history

3. TMI-1 fuel sample descriptions

4. Weights of TMI-1 fuel specimens

5. Enriched spiking standards

6. Measured nuclide contents and uncertainties for TMI-1 fuel samples (units of $\mathrm{mg} / \mathrm{g} \mathrm{U}$ initial)

7. TMI-1 reactor soluble boron concentration and moderator densities for fuel samples measured at ORNL

8. Fuel sample operating power and average moderator density

9. Ratio of calculated-to-experimental nuclide concentrations for the TMI-1 samples 
Table 1

\begin{tabular}{|c|c|}
\hline \multicolumn{2}{|l|}{ Assembly and reactor data } \\
\hline Assembly type & Mark B8 \\
\hline Lattice geometry & $15 \times 15$ \\
\hline Rod pitch $(\mathrm{cm})$ & 1.44272 \\
\hline Number of fuel rods & 208 \\
\hline Number of guide tubes & 16 \\
\hline Number of instrument tubes & 1 \\
\hline Assembly pitch $(\mathrm{cm})$ & 21.81098 \\
\hline \multicolumn{2}{|l|}{ Fuel rod data } \\
\hline Fuel material type & $\mathrm{UO}_{2}$ \\
\hline Fuel pellet density $\left(\mathrm{g} / \mathrm{cm}^{3}\right)$ & 10.196 \\
\hline Fuel pellet diameter $(\mathrm{cm})$ & 0.9362 \\
\hline Fuel temperature $(\mathrm{K})$ & see Table 5 \\
\hline Enrichment (wt \% ${ }^{233} \mathrm{U}$ ) & 4.013 \\
\hline Clad material & Zircaloy-4 \\
\hline Clad inner diameter $(\mathrm{cm})$ & 0.95758 \\
\hline Clad outer diameter $(\mathrm{cm})$ & 1.0922 \\
\hline Fuel rod length $(\mathrm{cm})$ & 390.804 \\
\hline Active fuel rod length $(\mathrm{cm})$ & 360.172 \\
\hline Bottom plenum length (nominal) $(\mathrm{cm})$ & 13.081 \\
\hline Average clad temperature $(\mathrm{K})$ & 640 \\
\hline \multicolumn{2}{|l|}{ Initial uranium composition (wt \%) } \\
\hline${ }^{234} \mathrm{U}$ & 0.040 \\
\hline${ }^{235} \mathrm{U}$ & 4.013 \\
\hline${ }^{238} \mathrm{U}$ & 95.947 \\
\hline \multicolumn{2}{|l|}{ Burnable poison rod (BPR) data } \\
\hline Number of poison rods inserted ${ }^{a}$ & 16 \\
\hline Absorber diameter $(\mathrm{cm})$ & 0.8636 \\
\hline Absorber material & $\mathrm{Al}_{2} \mathrm{O}_{3}-\mathrm{B}_{4} \mathrm{C}$ \\
\hline Absorber density $\left(\mathrm{g} / \mathrm{cm}^{3}\right)$ & 3.7 \\
\hline $\mathrm{B}_{4} \mathrm{C}$ content (wt \%) & 1.7 \\
\hline Clad inner diameter $(\mathrm{cm})$ & 0.9144 \\
\hline Clad outer diameter $(\mathrm{cm})$ & 1.0922 \\
\hline Cladding material & Zircaloy-4 \\
\hline \multicolumn{2}{|l|}{ Guide/instrument tube data } \\
\hline Guide/instrument tube material & Zircaloy-4 \\
\hline Guide tube inner diameter $(\mathrm{cm})$ & 1.26492 \\
\hline Guide tube outer diameter $(\mathrm{cm})$ & 1.3462 \\
\hline Instrument tube inner diameter $(\mathrm{cm})$ & 1.12014 \\
\hline Instrument tube outer diameter $(\mathrm{cm})$ & 1.25222 \\
\hline
\end{tabular}

${ }^{a}$ BPRs only present during cycle 9 . 
Table 2

\begin{tabular}{cccccccc}
\hline Cycle & $\begin{array}{c}\text { Start date } \\
(\mathrm{mm} / \mathrm{dd} / \mathrm{year})\end{array}$ & $\begin{array}{c}\text { End date } \\
(\mathrm{mm} / \mathrm{dd} / \mathrm{year})\end{array}$ & $\begin{array}{c}\text { Duration } \\
\text { (days) }\end{array}$ & $\begin{array}{c}\text { Down } \\
\text { time } \\
(\text { days })\end{array}$ & $\begin{array}{c}\text { EFPD } \\
(\text { days })\end{array}$ & $\begin{array}{c}\text { Capacity } \\
\text { factor }\end{array}$ & $\begin{array}{c}\text { Cycle } \\
\text { average } \\
\text { soluble } \\
\text { boron }^{b} \\
(\mathrm{ppm})\end{array}$ \\
\hline 9 & $11 / 14 / 1991$ & $9 / 10 / 1993$ & 666 & 36 & 639.4 & $96.0 \%$ & 833.8 \\
10 & $10 / 16 / 1993$ & $9 / 8 / 1995$ & 692 & 34 & 660.3 & $95.4 \%$ & 948.7 \\
\hline $\begin{array}{l}{ }^{a} \text { EFPD = effective full power days. } \\
{ }^{b} \text { Time-dependent boron is given in Table 7. }\end{array}$
\end{tabular}

Table 3

\begin{tabular}{|c|c|c|c|c|c|c|c|}
\hline $\begin{array}{l}\mathrm{AGHCF}^{a} \\
\operatorname{rod} \text { ID }\end{array}$ & $\begin{array}{l}\text { Rod } \\
\text { location }\end{array}$ & $\begin{array}{l}\text { Measurement } \\
\text { laboratory }\end{array}$ & $\begin{array}{l}\text { Sample } \\
\text { ID }\end{array}$ & $\begin{array}{l}\text { Position }{ }^{b} \\
(\mathrm{~mm})\end{array}$ & $\begin{array}{l}\text { Sample length } \\
(\mathrm{mm})\end{array}$ & $\begin{array}{l}\text { Sample burnup } \\
\% \text { FIMA } \\
\text { c,d }\end{array}$ & $\begin{array}{c}\text { Sample } \\
\text { burnup } \\
\left(\mathrm{GWd}_{d} \mathrm{t}\right)\end{array}$ \\
\hline \multirow{11}{*}{ AG536 } & \multirow{11}{*}{ H6 } & \multirow{11}{*}{ ANL } & A1B & 387 & 13 & & 44.8 \\
\hline & & & $\mathrm{B} 1 \mathrm{~B}$ & 1560 & 24 & & 54.5 \\
\hline & & & B3J & 770 & 16 & & 53.0 \\
\hline & & & $\mathrm{C} 2 \mathrm{~B}$ & 1946 & 13 & & 52.6 \\
\hline & & & D1A2 & 2619 & 13 & & 55.7 \\
\hline & & & D1A4 & 2924 & 13 & & 50.5 \\
\hline & & & $\mathrm{A} 2$ & 747 & 14 & & 50.6 \\
\hline & & & B2 & 1151 & 10 & & 50.1 \\
\hline & & & $\mathrm{C} 1$ & 2355 & 13 & & 50.2 \\
\hline & & & C3 & 1562 & 13 & & 51.3 \\
\hline & & & $\mathrm{D} 2$ & 3221 & 13 & & 44.8 \\
\hline \multirow[t]{2}{*}{ AG536 } & \multirow[t]{2}{*}{ H6 } & \multirow[t]{2}{*}{ ORNL } & C2D1 (TMI 3) ${ }^{e}$ & 1972 & 11 & 5.570 & 53.5 \\
\hline & & & C2D2 (TMI 4) ${ }^{e}$ & 2332 & 11 & 5.490 & 52.7 \\
\hline \multirow[t]{3}{*}{ AG616 } & \multirow[t]{3}{*}{ D5 } & \multirow[t]{3}{*}{ ORNL } & $\mathrm{A} 1\left(\right.$ TMI 1) ${ }^{e}$ & 3421 & 11 & 4.780 & 45.9 \\
\hline & & & B1 (TMI 2) ${ }^{e}$ & 2670 & 11 & 5.732 & 55.0 \\
\hline & & & B2 $\left(\right.$ TMI 5) ${ }^{e}$ & 2820 & 11 & 5.458 & 52.4 \\
\hline
\end{tabular}

\footnotetext{
${ }^{a}$ ANL Alpha Gamma Hot Cell Facility fuel rod identifier.

${ }^{b}$ Elevation measured from fuel rod bottom end plug.

${ }^{c}$ Percent fissions per initial metal atoms.

${ }^{d}$ Burnup as reported by measurement laboratories, based on the ASTM standard ${ }^{148} \mathrm{Nd}$ method.

${ }^{e}$ Sample identifiers used in the radiochemical assay measurements at ORNL.
} 
Table 4

\begin{tabular}{lccc}
\hline $\begin{array}{c}\text { Project } \\
\text { ID }\end{array}$ & $\begin{array}{c}\text { Fuel weight } \\
(\mathrm{g})\end{array}$ & MAS $(\mathrm{g})$ & $\begin{array}{c}\text { WS } \\
(\mathrm{g} \mathrm{MAS} / \mathrm{g} \text { WS})\end{array}$ \\
\hline TMI 1 (AG616 A1 ) & 6.438 & 124.786 & $0.2319 / 4.0350$ \\
TMI 2 (AG616 B1) & 6.456 & 128.839 & $0.2608 / 4.0636$ \\
TMI 3 (AG536 C2D1) & 6.532 & 126.992 & $0.2563 / 4.0606$ \\
TMI 4 (AG536 C2D2) & 6.501 & 128.761 & $0.2547 / 4.0589$ \\
TMI 5 (AG616 B2) & 7.069 & 127.777 & $0.2587 / 4.0712$ \\
\hline
\end{tabular}

Table 5

\begin{tabular}{ccc}
\hline Standard & Enriched isotope (atom\%) & Supplier \\
\hline $\mathrm{CsNO}_{3}$ solution & $\mathrm{Cs}-133(100)$ & Commercial vendor \\
$\mathrm{CeO}_{2}$ & $\mathrm{Ce}-140(99.84)$ & DOE NIDC \\
$\mathrm{Nd}_{2} \mathrm{O}_{3}$ & $\mathrm{Nd}-150(97.84)$ & DOE NIDC \\
$\mathrm{Sm}_{2} \mathrm{O}_{3}$ & $\mathrm{Sm}-152(99.44)$ & DOE NIDC \\
$\mathrm{Eu}_{2} \mathrm{O}_{3}$ & $\mathrm{Eu}-151(96.81)$ & DOE NIDC \\
$\mathrm{Gd}_{2} \mathrm{O}_{3}$ & $\mathrm{Gd}-155(94.31)$ & DOE NIDC \\
$\mathrm{CRM} \mathrm{111 \textrm {A }}$ & $\mathrm{U}-233(97.50)$ & NBL \\
Metal coupon & $\mathrm{Pu}-242(99.1)$ & ORNL Archives \\
\hline
\end{tabular}


Table 6

\begin{tabular}{|c|c|c|c|c|c|c|c|}
\hline Nuclide & $\begin{array}{c}\text { Measurement } \\
\text { method }\end{array}$ & $\begin{array}{c}\text { Measurement } \\
\text { date }\end{array}$ & $\begin{array}{c}\text { TMI } 1 \\
\text { AG616 A1 } \\
(45.9 \mathrm{GWd} / \mathrm{t}) \\
\end{array}$ & $\begin{array}{c}\text { TMI } 2 \\
\text { AG616 B1 } \\
(55.0 \mathrm{GWd} / \mathrm{t}) \\
\end{array}$ & $\begin{array}{c}\text { TMI } 3 \\
\text { AG536 C2D1 } \\
\text { (53.5 GWd/t) } \\
\end{array}$ & $\begin{array}{c}\text { TMI } 4 \\
\text { AG536 C2D2 } \\
(52.7 \mathrm{GWd} / \mathrm{t}) \\
\end{array}$ & $\begin{array}{c}\text { TMI 5 } \\
\text { AG616 B2 } \\
(52.4 \mathrm{GWd} / \mathrm{t}) \\
\end{array}$ \\
\hline${ }^{241} \mathrm{Am}$ & gamma spec $^{a}$ & $1 / 29 / 2013$ & $0.984 \pm 10 \%$ & $1.07 \pm 10 \%$ & $0.984 \pm 10 \%$ & $0.984 \pm 10 \%$ & $1.07 \pm 10 \%$ \\
\hline${ }^{134} \mathrm{Cs}$ & gamma spec & $1 / 29 / 2013$ & $0.000498 \pm 10 \%$ & $0.000665 \pm 10 \%$ & $0.00057 \pm 10 \%$ & $0.000641 \pm 10 \%$ & $0.00057 \pm 10 \%$ \\
\hline${ }^{137} \mathrm{Cs}$ & gamma spec & $1 / 29 / 2013$ & $1.02 \pm 10 \%$ & $1.2 \pm 10 \%$ & $1.1 \pm 10 \%$ & $1.24 \pm 10 \%$ & $1.13 \pm 10 \%$ \\
\hline${ }^{154} \mathrm{Eu}$ & gamma spec & $1 / 29 / 2013$ & $0.00727 \pm 10 \%$ & $0.00886 \pm 10 \%$ & $0.00807 \pm 10 \%$ & $0.0092 \pm 10 \%$ & $0.00863 \pm 10 \%$ \\
\hline${ }^{155} \mathrm{Eu}$ & gamma spec & $1 / 29 / 2013$ & $0.000821 \pm 10 \%$ & $0.00107 \pm 10 \%$ & $0.000632 \pm 10 \%$ & $0.000632 \pm 10 \%$ & $0.000695 \pm 10 \%$ \\
\hline $\begin{array}{l}{ }^{109} \mathrm{Ag} \\
\end{array}$ & ICPMS $^{c}$ & $9 / 17 / 2013$ & $0.112 \pm 10 \%$ & $0.129 \pm 10 \%$ & $0.123 \pm 10 \%$ & $0.123 \pm 10 \%$ & $0.105 \pm 10 \%$ \\
\hline${ }^{95} \mathrm{Mo}$ & ICPMS & $9 / 17 / 2013$ & $1.25 \pm 10 \%$ & $1.41 \pm 10 \%$ & $1.36 \pm 10 \%$ & $1.44 \pm 10 \%$ & $1.27 \pm 10 \%$ \\
\hline${ }^{103} \mathrm{Rh}$ & ICPMS & $9 / 17 / 2013$ & $0.788 \pm 10 \%$ & $0.798 \pm 10 \%$ & $0.729 \pm 10 \%$ & $0.804 \pm 10 \%$ & $0.691 \pm 10 \%$ \\
\hline${ }^{99} \mathrm{Tc}$ & ICPMS & $9 / 17 / 2013$ & $1.13 \pm 10 \%$ & $1.37 \pm 10 \%$ & $1.21 \pm 10 \%$ & $1.37 \pm 10 \%$ & $1.12 \pm 10 \%$ \\
\hline${ }^{237} \mathrm{~Np}$ & ICPMS & $9 / 17 / 2013$ & $0.781 \pm 10 \%$ & $0.993 \pm 10 \%$ & $0.992 \pm 10 \%$ & $0.984 \pm 10 \%$ & $0.953 \pm 10 \%$ \\
\hline${ }^{243} \mathrm{Am}$ & ICPMS & $9 / 17 / 2013$ & $0.195 \pm 10 \%$ & $0.342 \pm 10 \%$ & $0.313 \pm 10 \%$ & $0.317 \pm 10 \%$ & $0.3 \pm 10 \%$ \\
\hline${ }^{244} \mathrm{Cm}$ & ICPMS & $9 / 17 / 2013$ & $0.0416 \pm 10 \%$ & $0.0928 \pm 10 \%$ & $0.0847 \pm 10 \%$ & $0.0848 \pm 10 \%$ & $0.0785 \pm 10 \%$ \\
\hline${ }^{133} \mathrm{Cs}$ & ID-ICPMS $^{d}$ & $7 / 25 / 2013$ & $1.434 \pm 1.5 \%$ & $1.66 \pm 1.5 \%$ & $1.629 \pm 1.3 \%$ & $1.625 \pm 1.9 \%$ & $1.593 \pm 2.0 \%$ \\
\hline${ }^{134} \mathrm{Cs}$ & ID-ICPMS & $7 / 25 / 2013$ & $0.000461 \pm 18 \%$ & $0.00077 \pm 18 \%$ & $0.00084 \pm 20 \%$ & $0.00082 \pm 27 \%$ & $0.00071 \pm 20 \%$ \\
\hline${ }^{135} \mathrm{Cs}$ & ID-ICPMS & $7 / 25 / 2013$ & $0.5729 \pm 1.6 \%$ & $0.6108 \pm 1.6 \%$ & $0.6108 \pm 1.4 \%$ & $0.599 \pm 2.1 \%$ & $0.622 \pm 2.2 \%$ \\
\hline${ }^{137} \mathrm{Cs}$ & ID-ICPMS & $7 / 25 / 2013$ & $1.037 \pm 1.6 \%$ & $1.249 \pm 1.6 \%$ & $1.214 \pm 1.4 \%$ & $1.216 \pm 2.0 \%$ & $1.198 \pm 2.1 \%$ \\
\hline${ }^{140} \mathrm{Ce}$ & ID-ICPMS & $7 / 10 / 2013$ & $1.615 \pm 3.5 \%$ & $1.9 \pm 3.5 \%$ & $1.873 \pm 3.5 \%$ & $1.852 \pm 2.4 \%$ & $1.859 \pm 2.3 \%$ \\
\hline${ }^{142} \mathrm{Ce}$ & ID-ICPMS & $7 / 10 / 2013$ & $1.448 \pm 3.5 \%$ & $1.7 \pm 3.5 \%$ & $1.666 \pm 3.6 \%$ & $1.659 \pm 2.4 \%$ & $1.66 \pm 2.3 \%$ \\
\hline${ }^{142} \mathrm{Nd}$ & ID-ICPMS & $7 / 9 / 2013$ & $0.03107 \pm 2.1 \%$ & $0.04543 \pm 2.1 \%$ & $0.04278 \pm 2.0 \%$ & $0.04381 \pm 1.9 \%$ & $0.04109 \pm 1.7 \%$ \\
\hline${ }^{143} \mathrm{Nd}$ & ID-ICPMS & $7 / 9 / 2013$ & $1.083 \pm 1.9 \%$ & $1.16 \pm 1.9 \%$ & $1.148 \pm 2.0 \%$ & $1.145 \pm 1.7 \%$ & $1.158 \pm 1.6 \%$ \\
\hline${ }^{144} \mathrm{Nd}$ & ID-ICPMS & $7 / 9 / 2013$ & $1.884 \pm 1.7 \%$ & $2.333 \pm 1.7 \%$ & $2.236 \pm 1.8 \%$ & $2.278 \pm 1.6 \%$ & $2.192 \pm 1.4 \%$ \\
\hline${ }^{145} \mathrm{Nd}$ & ID-ICPMS & $7 / 9 / 2013$ & $0.919 \pm 1.9 \%$ & $1.05 \pm 1.9 \%$ & $1.02 \pm 2.0 \%$ & $1.029 \pm 1.8 \%$ & $1.013 \pm 1.6 \%$ \\
\hline${ }^{146} \mathrm{Nd}$ & ID-ICPMS & $7 / 9 / 2013$ & $0.984 \pm 1.9 \%$ & $1.207 \pm 1.9 \%$ & $1.163 \pm 2.0 \%$ & $1.175 \pm 1.8 \%$ & $1.144 \pm 1.5 \%$ \\
\hline${ }^{148} \mathrm{Nd}$ & ID-ICPMS & $7 / 9 / 2013$ & $0.5062 \pm 1.9 \%$ & $0.608 \pm 1.9 \%$ & $0.586 \pm 2.1 \%$ & $0.592 \pm 1.9 \%$ & $0.5799 \pm 1.7 \%$ \\
\hline${ }^{150} \mathrm{Nd}$ & ID-ICPMS & $7 / 9 / 2013$ & $0.2403 \pm 1.8 \%$ & $0.2939 \pm 1.8 \%$ & $0.2798 \pm 1.9 \%$ & $0.2861 \pm 1.8 \%$ & $0.2787 \pm 1.6 \%$ \\
\hline${ }^{147} \mathrm{Sm}$ & ID-ICPMS & $7 / 9 / 2013$ & $0.3263 \pm 1.6 \%$ & $0.3386 \pm 1.6 \%$ & $0.3363 \pm 1.6 \%$ & $0.3383 \pm 1.3 \%$ & $0.3367 \pm 1.7 \%$ \\
\hline${ }^{148} \mathrm{Sm}$ & ID-ICPMS & $7 / 9 / 2013$ & $0.2204 \pm 1.6 \%$ & $0.2853 \pm 1.6 \%$ & $0.2767 \pm 1.5 \%$ & $0.2782 \pm 1.4 \%$ & $0.274 \pm 1.7 \%$ \\
\hline${ }^{149} \mathrm{Sm}$ & ID-ICPMS & 7/9/2013 & $0.00419 \pm 2.4 \%$ & $0.00365 \pm 2.4 \%$ & $0.003538 \pm 2.0 \%$ & $0.003444 \pm 2.3 \%$ & $0.003726 \pm 2.1 \%$ \\
\hline${ }^{150} \mathrm{Sm}$ & ID-ICPMS & $7 / 9 / 2013$ & $0.387 \pm 1.6 \%$ & $0.4689 \pm 1.6 \%$ & $0.4552 \pm 1.5 \%$ & $0.4599 \pm 1.3 \%$ & $0.4522 \pm 1.7 \%$ \\
\hline
\end{tabular}




\begin{tabular}{|c|c|c|c|c|c|c|c|c|}
\hline${ }^{151} \mathrm{Sm}$ & ID-ICPMS & $7 / 9 / 2013$ & $0.01579 \pm 2.5 \%$ & $0.01394 \pm 2.5 \%$ & $0.0141 \pm 2.0 \%$ & $0.01367 \pm 1.8 \%$ & 0.01477 & $\pm 2.4 \%$ \\
\hline${ }^{152} \mathrm{Sm}$ & ID-ICPMS & $7 / 9 / 2013$ & $0.1297 \pm 2.2 \%$ & $0.1442 \pm 2.2 \%$ & $0.1381 \pm 1.7 \%$ & $0.1416 \pm 1.5 \%$ & 0.1387 & $\pm 1.8 \%$ \\
\hline${ }^{154} \mathrm{Sm}$ & ID-ICPMS & 7/9/2013 & $0.0502 \pm 2.0 \%$ & $0.0625 \pm 2.0 \%$ & $0.0602 \pm 1.7 \%$ & $0.06048 \pm 1.5 \%$ & 0.0597 & $\pm 1.8 \%$ \\
\hline${ }^{151} \mathrm{Eu}$ & ID-ICPMS & $7 / 8 / 2013$ & $0.001995 \pm 2.3 \%$ & $0.002112 \pm 2.3 \%$ & $0.002081 \pm 2.7 \%$ & $0.002081 \pm 2.4 \%$ & 0.002136 & $\pm 2.7 \%$ \\
\hline${ }^{152} \mathrm{Eu}$ & ID-ICPMS & $7 / 8 / 2013$ & $0.000173 \pm 5.9 \%$ & $0.000267 \pm 5.9 \%$ & $6.24 \mathrm{E}-05 \pm 11 \%$ & $0.000268 \pm 6.3 \%$ & 0.000116 & $\pm 4.2 \%$ \\
\hline${ }^{153} \mathrm{Eu}$ & ID-ICPMS & $7 / 8 / 2013$ & $0.1521 \pm 1.9 \%$ & $0.1823 \pm 1.9 \%$ & $0.1762 \pm 1.9 \%$ & $0.1782 \pm 2.0 \%$ & 0.1764 & $\pm 2 \%$ \\
\hline${ }^{154} \mathrm{Eu}$ & ID-ICPMS & $7 / 8 / 2013$ & $0.00777 \pm 2.0 \%$ & $0.00962 \pm 2.0 \%$ & $0.00964 \pm 2.2 \%$ & $0.00958 \pm 2.0 \%$ & 0.00971 & $\pm 2.1 \%$ \\
\hline${ }^{155} \mathrm{Eu}$ & ID-ICPMS & $7 / 8 / 2013$ & $0.000829 \pm 2.5 \%$ & $0.001034 \pm 2.5 \%$ & $0.001011 \pm 2.5 \%$ & $0.001059 \pm 2.4 \%$ & 0.000996 & $2.9 \%$ \\
\hline
\end{tabular}

${ }^{a}$ Gamma ray spectroscopy on the dissolved solution.

${ }^{b}$ Uncertainties are given as the 2 -sigma (95\% confidence) values.

${ }^{c}$ Quadrupole ICPMS with external calibration.

${ }^{d}$ HPLC separations and quadrupole ICPMS isotopic dilution internal calibration. 
Table 6 (cont.)

\begin{tabular}{|c|c|c|c|c|c|c|c|}
\hline Nuclide & $\begin{array}{c}\text { Measurement } \\
\text { Method }\end{array}$ & $\begin{array}{c}\text { Measurement } \\
\text { Date }\end{array}$ & $\begin{array}{c}\text { TMI } 1 \\
\text { AG616 A1 } \\
(45.9 \mathrm{GWd} / \mathrm{t})\end{array}$ & $\begin{array}{c}\text { TMI } 2 \\
\text { AG616 B1 } \\
(55.0 \mathrm{GWd} / \mathrm{t})\end{array}$ & $\begin{array}{c}\text { TMI } 3 \\
\text { AG536 C2D1 } \\
(53.5 \mathrm{GWd} / \mathrm{t})\end{array}$ & $\begin{array}{c}\text { TMI } 4 \\
\text { AG536 C2D2 } \\
(52.7 \mathrm{GWd} / \mathrm{t})\end{array}$ & $\begin{array}{c}\text { TMI } 5 \\
\text { AG616 B2 } \\
(52.4 \mathrm{GWd} / \mathrm{t})\end{array}$ \\
\hline${ }^{152} \mathrm{Gd}$ & ID-ICPMS & $7 / 8 / 2013$ & $0.000178 \pm 7.2 \%$ & $0.000183 \pm 7.2 \%$ & $0.000069 \pm 16 \%$ & $0.000196 \pm 6 / 0 \%$ & $0.00011 \pm 9.8 \%$ \\
\hline${ }^{154} \mathrm{Gd}$ & ID-ICPMS & $7 / 8 / 2013$ & $0.02967 \pm 2.0 \%$ & $0.03647 \pm 2.0 \%$ & $0.03631 \pm 1.8 \%$ & $0.03588 \pm 2.0 \%$ & $0.0366 \pm 2.9 \%$ \\
\hline${ }^{155} \mathrm{Gd}$ & ID-ICPMS & $7 / 8 / 2013$ & $0.01063 \pm 1.9 \%$ & $0.0133 \pm 1.9 \%$ & $0.0128 \pm 1.8 \%$ & $0.01295 \pm 2.0 \%$ & $0.01266 \pm 1.9 \%$ \\
\hline${ }^{156} \mathrm{Gd}$ & ID-ICPMS & $7 / 8 / 2013$ & $0.1375 \pm 1.7 \%$ & $0.2131 \pm 1.7 \%$ & $0.1994 \pm 1.6 \%$ & $0.2031 \pm 1.8 \%$ & $0.1931 \pm 1.6 \%$ \\
\hline${ }^{157} \mathrm{Gd}$ & ID-ICPMS & $7 / 8 / 2013$ & $0.00021 \pm 8.4 \%$ & $0.000184 \pm 8.4 \%$ & $0.000199 \pm 4.9 \%$ & $0.000204 \pm 6.4 \%$ & $0.000246 \pm 7.6 \%$ \\
\hline${ }^{158} \mathrm{Gd}$ & ID-ICPMS & $7 / 8 / 2013$ & $0.0227 \pm 1.9 \%$ & $0.03241 \pm 1.9 \%$ & $0.03044 \pm 1.7 \%$ & $0.03074 \pm 2.0 \%$ & $0.03015 \pm 1.8 \%$ \\
\hline${ }^{160} \mathrm{Gd}$ & ID-ICPMS & $7 / 8 / 2013$ & $0.001581 \pm 2.2 \%$ & $0.002016 \pm 2.2 \%$ & $0.001904 \pm 2.1 \%$ & $0.00193 \pm 2.9 \%$ & $0.001912 \pm 2.4 \%$ \\
\hline${ }^{233} \mathrm{U}-$ & ID-ICPMS & $6 / 19 / 2013$ & $0.00071 \pm 100 \%$ & $0.00047 \pm 100 \%$ & $0.00044 \pm 100 \%$ & $0.00065 \pm 100 \%$ & $0.00059 \pm 100 \%$ \\
\hline${ }^{234} \mathrm{U}$ & ID-ICPMS & $6 / 19 / 2013$ & $0.2285 \pm 2.4 \%$ & $0.2191 \pm 2.4 \%$ & $0.2193 \pm 2.4 \%$ & $0.2246 \pm 4.1 \%$ & $0.221 \pm 25 \%$ \\
\hline${ }^{235} \mathrm{U}$ & ID-ICPMS & $6 / 19 / 2013$ & $9.14 \pm 2.4 \%$ & $6.31 \pm 2.4 \%$ & $6.91 \pm 1.3 \%$ & $6.57 \pm 2.1 \%$ & $7.37 \pm 1.8 \%$ \\
\hline${ }^{236} \mathrm{U}$ & ID-ICPMS & $6 / 19 / 2013$ & $5.42 \pm 2.4 \%$ & $5.69 \pm 2.4 \%$ & $5.68 \pm 1.9 \%$ & $5.66 \pm 2.2 \%$ & $5.66 \pm 2.2 \%$ \\
\hline${ }^{238} \mathrm{U}$ & ID-ICPMS & $6 / 19 / 2013$ & $933 \pm 1.1 \%$ & $928 \pm 1.1 \%$ & $934 \pm 1.0 \%$ & $931 \pm 1.3 \%$ & $930 \pm 1.6 \%$ \\
\hline${ }^{238} \mathrm{Pu}$ & ID-ICPMS & $11 / 22 / 2013$ & $0.2715 \pm 1.8 \%$ & $0.3722 \pm 1.8 \%$ & $0.3903 \pm 2.4 \%$ & $0.3641 \pm 1.1 \%$ & $0.344 \pm 2.9 \%$ \\
\hline${ }^{239} \mathrm{Pu}$ & ID-ICPMS & $11 / 22 / 2013$ & $5.916 \pm 1.4 \%$ & $5.851 \pm 1.4 \%$ & $6.115 \pm 1.5 \%$ & $5.842 \pm 1.0 \%$ & $6.28 \pm 1.6 \%$ \\
\hline${ }^{240} \mathrm{Pu}$ & ID-ICPMS & $11 / 22 / 2013$ & $2.762 \pm 1.5 \%$ & $3.124 \pm 1.5 \%$ & $3.191 \pm 1.8 \%$ & $3.099 \pm 1.1 \%$ & $3.166 \pm 1.7 \%$ \\
\hline${ }^{241} \mathrm{Pu}$ & ID-ICPMS & $11 / 22 / 2013$ & $0.702 \pm 1.9 \%$ & $0.778 \pm 1.9 \%$ & $0.782 \pm 2.0 \%$ & $0.746 \pm 1.5 \%$ & $0.801 \pm 2.5 \%$ \\
\hline${ }^{242} \mathrm{Pu}$ & ID-ICPMS & $11 / 22 / 2013$ & $0.765 \pm 1.6 \%$ & $1.097 \pm 1.6 \%$ & $1.012 \pm 1.7 \%$ & $1.011 \pm 1.3 \%$ & $1.003 \pm 2.0 \%$ \\
\hline
\end{tabular}

${ }^{a}$ Gamma ray spectroscopy on the dissolved solution.

${ }^{b}$ Uncertainties are given as the 2-sigma (95\% confidence) values.

${ }^{c}$ Quadrupole ICPMS with external calibration.

${ }^{d}$ HPLC separations and quadrupole ICPMS isotopic dilution internal calibration. 
Table 7

\begin{tabular}{|c|c|c|c|c|c|c|c|}
\hline \multirow[b]{2}{*}{ Cycle } & & Sample ID & AG616 A1 & AG616 B1 & AG536 C2D1 & AG536 C2D2 & AG616 B2 \\
\hline & $\begin{array}{c}\text { Time } \\
\left.\text { (EFPD }{ }^{a} \text { days }\right)\end{array}$ & $\begin{array}{c}\text { Boron } \\
\text { concentration } \\
(\mathrm{ppm})\end{array}$ & \multicolumn{5}{|c|}{$\begin{array}{l}\text { Moderator density } \\
\qquad\left(\mathrm{g} / \mathrm{cm}^{3}\right)\end{array}$} \\
\hline \multirow{11}{*}{9} & 0.0 & 1670 & 0.6759 & 0.6935 & 0.7057 & 0.6965 & 0.6876 \\
\hline & 74.2 & 1481 & 0.6759 & 0.6935 & 0.7057 & 0.6965 & 0.6876 \\
\hline & 144.1 & 1342 & 0.6759 & 0.6905 & 0.7057 & 0.6965 & 0.6876 \\
\hline & 214.0 & 1175 & 0.6731 & 0.6905 & 0.7057 & 0.6965 & 0.6876 \\
\hline & 284.9 & 990 & 0.6759 & 0.6905 & 0.7057 & 0.6965 & 0.6876 \\
\hline & 349.7 & 772 & 0.6759 & 0.6935 & 0.7057 & 0.6965 & 0.6876 \\
\hline & 425.0 & 545 & 0.6759 & 0.6935 & 0.7057 & 0.6965 & 0.6876 \\
\hline & 483.9 & 352 & 0.6759 & 0.6935 & 0.7057 & 0.6965 & 0.6935 \\
\hline & 549.2 & 134 & 0.6788 & 0.6935 & 0.7057 & 0.6996 & 0.6905 \\
\hline & 608.0 & 13 & 0.6846 & 0.7026 & 0.7152 & 0.7057 & 0.6965 \\
\hline & 639.4 & 2 & 0.7026 & 0.7088 & 0.7152 & 0.7120 & 0.7088 \\
\hline \multirow{11}{*}{10} & 0.0 & 1800 & 0.6846 & 0.6996 & 0.7120 & 0.7026 & 0.6965 \\
\hline & 68.0 & 1649 & 0.6876 & 0.6996 & 0.7120 & 0.7057 & 0.6965 \\
\hline & 131.8 & 1521 & 0.6876 & 0.7026 & 0.7120 & 0.7057 & 0.6965 \\
\hline & 209.0 & 1322 & 0.6876 & 0.7026 & 0.7120 & 0.7057 & 0.6965 \\
\hline & 272.1 & 1140 & 0.6876 & 0.7026 & 0.7120 & 0.7057 & 0.6996 \\
\hline & 347.4 & 918 & 0.6876 & 0.7026 & 0.7120 & 0.7057 & 0.6996 \\
\hline & 416.4 & 718 & 0.6876 & 0.7026 & 0.7120 & 0.7057 & 0.6996 \\
\hline & 486.4 & 506 & 0.6876 & 0.7026 & 0.7120 & 0.7057 & 0.6996 \\
\hline & 556.3 & 298 & 0.6905 & 0.7026 & 0.7120 & 0.7057 & 0.6996 \\
\hline & 626.1 & 103 & 0.6905 & 0.7026 & 0.7120 & 0.7057 & 0.6996 \\
\hline & 660.3 & 1.8 & 0.6905 & 0.7026 & 0.7120 & 0.7057 & 0.6996 \\
\hline
\end{tabular}

${ }^{a}$ EFPD $=$ effective full power days 
Table 8

\begin{tabular}{|c|c|c|c|c|c|c|c|c|c|c|c|}
\hline \multirow[b]{2}{*}{ Cycle } & Sample ID & $\begin{array}{c}\text { AG616 } \\
\text { A1 }\end{array}$ & $\begin{array}{c}\text { AG616 } \\
\text { B1 }\end{array}$ & $\begin{array}{l}\text { AG536 } \\
\text { C2D1 }\end{array}$ & $\begin{array}{l}\text { AG536 } \\
\text { C2D2 }\end{array}$ & $\begin{array}{c}\text { AG616 } \\
\text { B2 }\end{array}$ & $\begin{array}{c}\text { AG616 } \\
\text { A1 }\end{array}$ & $\begin{array}{c}\text { AG616 } \\
\text { B1 }\end{array}$ & $\begin{array}{l}\text { AG536 } \\
\text { C2D1 }\end{array}$ & $\begin{array}{l}\text { AG536 } \\
\text { C2D2 }\end{array}$ & $\begin{array}{c}\text { AG616 } \\
\text { B2 }\end{array}$ \\
\hline & $\begin{array}{c}\text { Time } \\
\text { (EFPD }^{a} \text { days) }\end{array}$ & & & $\begin{array}{l}\text { Specific } \\
\text { power } \\
(\mathrm{MW} / \mathrm{t})\end{array}$ & & & & & $\begin{array}{c}\text { Fuel } \\
\text { temperat } \\
\text { ure }(\mathrm{K})\end{array}$ & & \\
\hline \multirow{11}{*}{9} & 0.0 & & & & & & & & & & \\
\hline & 74.2 & 30.580 & 45.667 & 59.593 & 57.447 & 42.156 & 960.5 & 1084.7 & 1105.7 & 1098.3 & 1078.9 \\
\hline & 144.1 & 33.309 & 46.386 & 61.186 & 59.904 & 43.398 & 961.5 & 1052.2 & 1069.1 & 1062.9 & 1051.2 \\
\hline & 214.0 & 34.811 & 46.759 & 49.444 & 48.519 & 44.038 & 946.9 & 1019.4 & 1034.4 & 1029.4 & 1020.5 \\
\hline & 284.9 & 36.595 & 46.968 & 51.461 & 50.779 & 44.593 & 952.7 & 992.9 & 1003.2 & 998.2 & 997.5 \\
\hline & 349.7 & 38.559 & 46.643 & 48.619 & 48.235 & 44.621 & 937.6 & 967.5 & 976.0 & 971.2 & 972.7 \\
\hline & 425.0 & 39.506 & 45.929 & 46.401 & 45.959 & 44.103 & 931.7 & 939.4 & 948.9 & 944.2 & 946.0 \\
\hline & 483.9 & 40.747 & 45.266 & 44.420 & 44.163 & 43.651 & 920.8 & 920.4 & 925.5 & 920.6 & 926.4 \\
\hline & 549.2 & 41.338 & 44.218 & 42.577 & 42.217 & 42.708 & 908.9 & 903.1 & 907.8 & 903.4 & 909.2 \\
\hline & 608.0 & 41.700 & 44.348 & 42.919 & 42.398 & 42.575 & 918.9 & 905.2 & 900.2 & 889.6 & 910.5 \\
\hline & 639.4 & 46.740 & 47.275 & 44.289 & 46.160 & 45.834 & 750.5 & 725.3 & 810.4 & 791.0 & 731.5 \\
\hline \multirow{11}{*}{10} & 0.0 & & & & & & & & & & \\
\hline & 68.0 & 29.608 & 42.294 & 47.189 & 45.013 & 39.052 & 796.1 & 858.9 & 871.0 & 871.3 & 851.5 \\
\hline & 131.8 & 30.270 & 41.396 & 37.149 & 35.898 & 38.583 & 808.4 & 849.5 & 856.6 & 853.5 & 847.4 \\
\hline & 209.0 & 31.505 & 40.445 & 34.614 & 34.028 & 38.109 & 809.1 & 841.1 & 844.7 & 838.8 & 841.9 \\
\hline & 272.1 & 32.566 & 39.837 & 33.132 & 32.902 & 37.861 & 809.7 & 834.9 & 835.8 & 829.3 & 837.4 \\
\hline & 347.4 & 33.557 & 39.289 & 32.086 & 32.032 & 37.578 & 812.3 & 828.0 & 828.5 & 822.1 & 831.5 \\
\hline & 416.4 & 34.376 & 38.776 & 31.160 & 31.244 & 37.247 & 814.8 & 822.2 & 821.7 & 815.2 & 826.6 \\
\hline & 486.4 & 34.969 & 38.252 & 30.327 & 30.460 & 36.843 & 816.3 & 815.7 & 815.3 & 808.5 & 820.6 \\
\hline & 556.3 & 35.346 & 37.664 & 29.549 & 29.608 & 36.340 & 817.3 & 808.6 & 808.4 & 801.6 & 813.9 \\
\hline & 626.1 & 35.799 & 37.120 & 28.837 & 28.852 & 35.851 & 816.5 & 803.8 & 802.7 & 796.2 & 808.7 \\
\hline & 660.3 & 36.045 & 36.720 & 28.359 & 28.383 & 35.509 & 812.8 & 802.2 & 799.9 & 794.4 & 806.5 \\
\hline
\end{tabular}

${ }^{a} \mathrm{EFPD}=$ effective full power days 
Table 9

\begin{tabular}{|c|c|c|c|c|c|c|c|c|}
\hline Nuclide & $\begin{array}{c}\text { TMI 1 } \\
\text { AG616 A1 } \\
(46.1 \mathrm{GWd} / \mathrm{t})^{a}\end{array}$ & $\begin{array}{c}\text { TMI } 2 \\
\text { AG616 B1 } \\
(55.3 \mathrm{GWd} / \mathrm{t})\end{array}$ & $\begin{array}{c}\text { TMI } 3 \\
\text { AG536 C2D1 } \\
(53.8 \mathrm{GWd} / \mathrm{t})\end{array}$ & $\begin{array}{c}\text { TMI } 4 \\
\text { AG536 C2D2 } \\
(53.1 \mathrm{GWd} / \mathrm{t})\end{array}$ & $\begin{array}{c}\text { TMI }^{b} \\
\text { AG616 B2 } \\
(52.6 \mathrm{GWd} / \mathrm{t})\end{array}$ & $\begin{array}{c}\text { Average } \\
\mathrm{C} / \mathrm{E}^{c}\end{array}$ & $\begin{array}{c}\mathrm{RSD} \text { of } \\
\mathrm{C} / \mathrm{E}(\%)^{c}\end{array}$ & $\begin{array}{c}\text { Measurement } \\
\text { uncertainty } \\
\text { (1-sigma) }\end{array}$ \\
\hline${ }^{233} \mathrm{U}$ & 0.011 & 0.018 & 0.014 & 0.020 & 0.014 & 0.016 & 25 & 50 \\
\hline${ }^{234} \mathrm{U}$ & 0.958 & 0.951 & 0.944 & 0.970 & 0.953 & 0.956 & 1.2 & 3.8 \\
\hline${ }^{235} \mathrm{U}$ & 0.948 & 0.932 & 0.963 & 0.952 & 0.889 & 0.948 & 1.3 & 1.0 \\
\hline${ }^{236} \mathrm{U}$ & 1.028 & 1.025 & 1.020 & 1.015 & 1.021 & 1.022 & 0.6 & 1.1 \\
\hline${ }^{238} \mathrm{U}$ & 0.992 & 0.989 & 0.986 & 0.983 & 0.989 & 0.988 & 0.4 & 0.7 \\
\hline${ }^{238} \mathrm{Pu}$ & 0.966 & 0.978 & 0.959 & 0.880 & 0.966 & 0.946 & 4.7 & 1.1 \\
\hline${ }^{239} \mathrm{Pu}$ & 1.044 & 1.041 & 1.064 & 1.028 & 0.967 & 1.044 & 1.4 & 0.8 \\
\hline${ }^{240} \mathrm{Pu}$ & 1.050 & 1.047 & 1.066 & 1.028 & 1.000 & 1.048 & 1.5 & 0.8 \\
\hline${ }^{241} \mathrm{Pu}$ & 1.045 & 1.040 & 1.064 & 1.016 & 0.981 & 1.041 & 1.9 & 1.0 \\
\hline${ }^{242} \mathrm{Pu}$ & 1.000 & 0.988 & 0.991 & 0.963 & 0.989 & 0.986 & 1.6 & 0.8 \\
\hline${ }^{237} \mathrm{~Np}$ & 0.859 & 0.802 & 0.793 & 0.780 & 0.797 & 0.808 & 4.3 & 5.0 \\
\hline${ }^{241} \mathrm{Am}$ & 1.071 & 1.073 & 1.156 & 1.149 & 1.035 & 1.112 & 4.2 & 5.0 \\
\hline${ }^{243} \mathrm{Am}$ & 0.977 & 0.897 & 0.892 & 0.873 & 0.902 & 0.910 & 5.1 & 5.0 \\
\hline${ }^{244} \mathrm{Cm}$ & 0.925 & 0.841 & 0.823 & 0.785 & 0.822 & 0.843 & 7.0 & 5.0 \\
\hline${ }^{133} \mathrm{Cs}$ & 1.045 & 1.033 & 1.037 & 1.023 & 1.040 & 1.035 & 0.9 & 0.9 \\
\hline${ }^{134} \mathrm{Cs}$ & 0.841 & 0.902 & 0.865 & 1.019 & 1.032 & 0.870 & 17 & 12 \\
\hline${ }^{135} \mathrm{Cs}$ & 1.020 & 1.000 & 1.010 & 0.992 & 0.967 & 1.006 & 1.2 & 0.9 \\
\hline${ }^{137} \mathrm{Cs}$ & 1.055 & 1.047 & 1.045 & 1.033 & 1.041 & 1.045 & 0.9 & 0.9 \\
\hline${ }^{140} \mathrm{Ce}$ & 1.060 & 1.072 & 1.072 & 1.046 & 1.046 & 1.063 & 1.2 & 1.4 \\
\hline${ }^{142} \mathrm{Ce}$ & 1.059 & 1.069 & 1.067 & 1.048 & 1.046 & 1.061 & 0.9 & 1.4 \\
\hline${ }^{142} \mathrm{Nd}$ & 1.018 & 1.034 & 1.009 & 1.001 & 1.029 & 1.016 & 1.4 & 1.0 \\
\hline${ }^{143} \mathrm{Nd}$ & 0.970 & 0.971 & 0.979 & 0.974 & 0.956 & 0.974 & 0.4 & 0.9 \\
\hline${ }^{144} \mathrm{Nd}$ & 0.966 & 0.965 & 0.955 & 0.956 & 0.971 & 0.960 & 0.6 & 0.8 \\
\hline${ }^{145} \mathrm{Nd}$ & 0.962 & 0.957 & 0.959 & 0.957 & 0.960 & 0.959 & 0.2 & 0.9 \\
\hline${ }^{146} \mathrm{Nd}$ & 0.996 & 0.996 & 0.993 & 0.987 & 0.994 & 0.993 & 0.4 & 0.9 \\
\hline${ }^{148} \mathrm{Nd}$ & 1.003 & 1.000 & 0.999 & 0.996 & 0.999 & 0.999 & 0.3 & 1.0 \\
\hline${ }^{150} \mathrm{Nd}$ & 1.025 & 1.021 & 1.018 & 1.026 & 1.020 & 1.023 & 0.4 & 0.9 \\
\hline${ }^{147} \mathrm{Sm}$ & 0.992 & 0.991 & 0.994 & 0.996 & 0.991 & 0.993 & 0.2 & 0.9 \\
\hline${ }^{148} \mathrm{Sm}$ & 0.945 & 0.947 & 0.936 & 0.924 & 0.918 & 0.938 & 1.1 & 0.9 \\
\hline
\end{tabular}




\begin{tabular}{|c|c|c|c|c|c|c|c|c|}
\hline${ }^{149} \mathrm{Sm}$ & 0.900 & 1.093 & 1.071 & 1.046 & 1.054 & 1.027 & 8.5 & 1.2 \\
\hline${ }^{150} \mathrm{Sm}$ & 1.030 & 1.034 & 1.023 & 1.019 & 1.017 & 1.027 & 0.7 & 0.9 \\
\hline${ }^{151} \mathrm{Sm}$ & 0.791 & 0.946 & 0.967 & 0.943 & 0.873 & 0.911 & 8.9 & 1.3 \\
\hline${ }^{152} \mathrm{Sm}$ & 0.995 & 0.996 & 1.007 & 1.021 & 1.009 & 1.005 & 1.2 & 1.0 \\
\hline${ }^{154} \mathrm{Sm}$ & 1.044 & 1.083 & 1.071 & 1.057 & 1.057 & 1.064 & 1.6 & 0.9 \\
\hline${ }^{151} \mathrm{Eu}$ & 0.932 & 0.928 & 0.946 & 0.951 & 0.897 & 0.939 & 1.2 & 1.3 \\
\hline${ }^{152} \mathrm{Eu}$ & 0.029 & 0.016 & 0.019 & 0.085 & 0.037 & 0.037 & 86 & 3.3 \\
\hline${ }^{153} \mathrm{Eu}$ & 1.065 & 1.064 & 1.055 & 1.053 & 1.049 & 1.059 & 0.6 & 0.9 \\
\hline${ }^{154} \mathrm{Eu}$ & 1.134 & 1.136 & 1.107 & 1.091 & 1.060 & 1.117 & 2.0 & 1.0 \\
\hline${ }^{155} \mathrm{Eu}$ & 1.051 & 1.062 & 1.000 & 1.031 & 1.039 & 1.036 & 2.6 & 1.3 \\
\hline${ }^{152} \mathrm{Gd}$ & 0.227 & 0.198 & 0.202 & 0.587 & 0.336 & 0.304 & 62 & 4.9 \\
\hline${ }^{154} \mathrm{Gd}$ & 1.092 & 1.109 & 1.101 & 1.078 & 1.038 & 1.095 & 1.2 & 1.1 \\
\hline${ }^{155} \mathrm{Gd}$ & 1.040 & 1.047 & 1.038 & 1.034 & 1.035 & 1.040 & 0.5 & 1.0 \\
\hline${ }^{156} \mathrm{Gd}$ & 0.987 & 0.993 & 0.971 & 0.955 & 0.973 & 0.977 & 1.8 & 0.9 \\
\hline${ }^{157} \mathrm{Gd}$ & 0.684 & 1.016 & 0.838 & 0.859 & 0.702 & 0.849 & 16 & 3.4 \\
\hline${ }^{158} \mathrm{Gd}$ & 1.176 & 1.231 & 1.208 & 1.185 & 1.182 & 1.200 & 2.1 & 1.0 \\
\hline${ }^{160} \mathrm{Gd}$ & 0.993 & 1.048 & 1.040 & 1.033 & 1.018 & 1.028 & 2.4 & 1.2 \\
\hline${ }^{109} \mathrm{Ag}$ & 0.972 & 1.067 & 1.087 & 1.069 & 1.228 & 1.049 & 5.0 & 5.0 \\
\hline${ }^{95} \mathrm{Mo}$ & 0.813 & 0.833 & 0.796 & 0.833 & 0.888 & 0.819 & 2.2 & 5.0 \\
\hline${ }^{103} \mathrm{Rh}$ & 0.795 & 0.890 & 0.867 & 0.948 & 0.994 & 0.875 & 7.2 & 5.0 \\
\hline${ }^{99} \mathrm{Tc}$ & 0.944 & 0.899 & 0.881 & 0.985 & 1.065 & 0.927 & 5.1 & 5.0 \\
\hline
\end{tabular}

${ }^{a}$ Burnup values used in calculations were adjusted to improve agreement with measured ${ }^{148} \mathrm{Nd}$.

${ }^{b}$ Sample AG616 B2 was from an assembly grid spacer location.

${ }^{c}$ The average C/E and standard deviation excludes sample AG616 B2 due to its proximity to a spacer grid, which was not consider in the calculation model. 
Figure 1

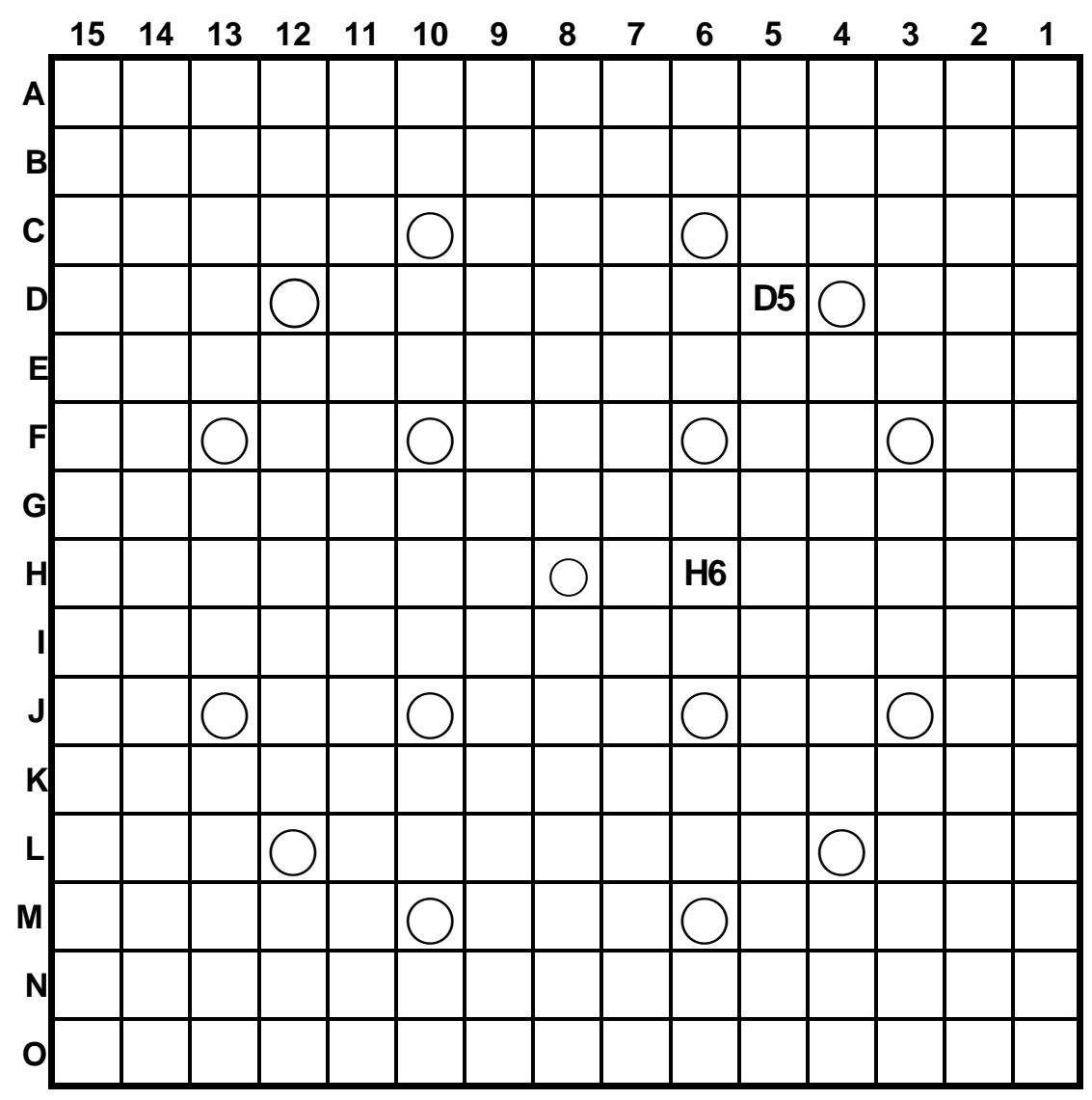

Fuel rod

$\bigcirc$ Guide tube/ Instrument tube 
Figure 2

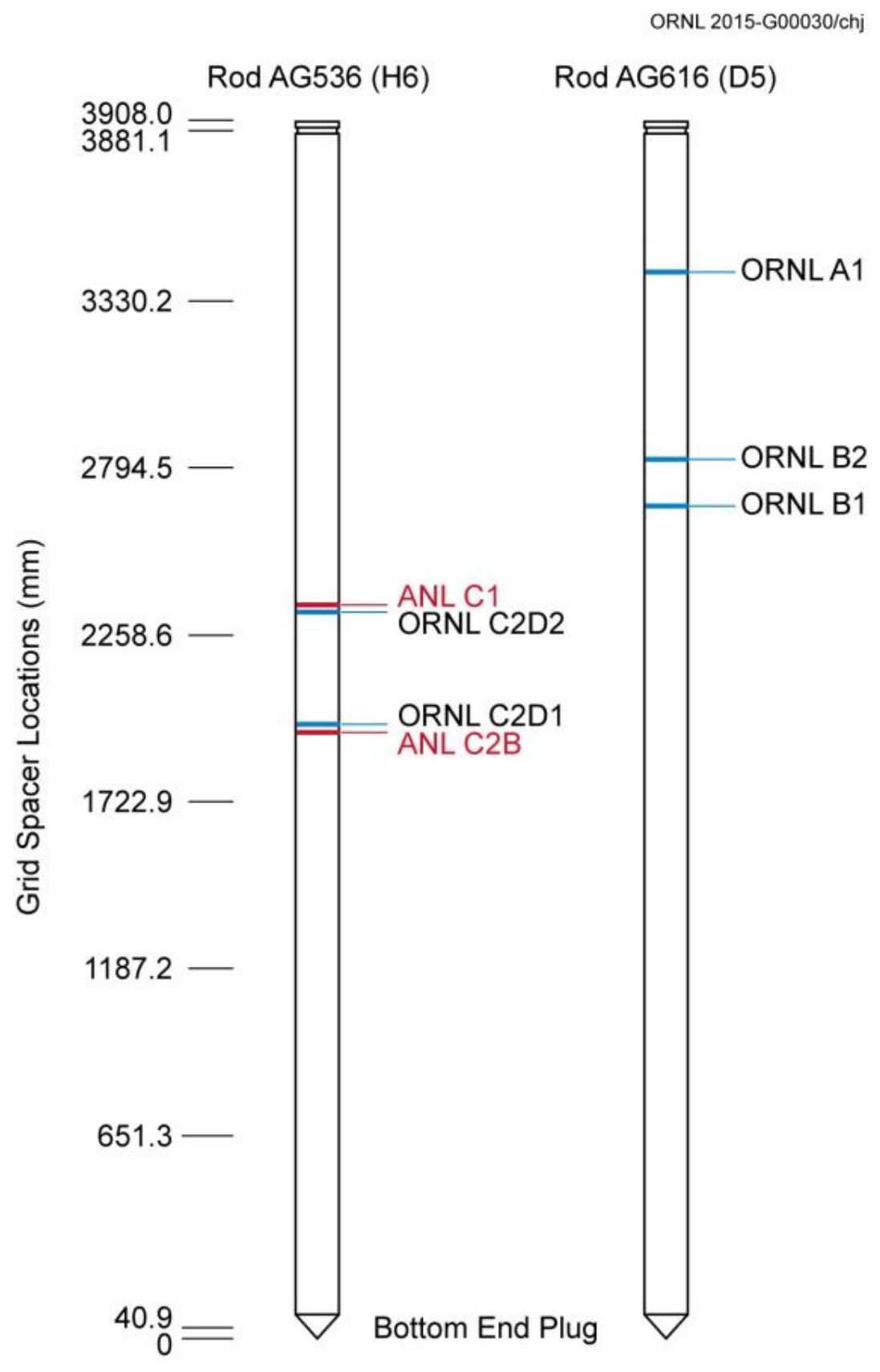


Figure 3

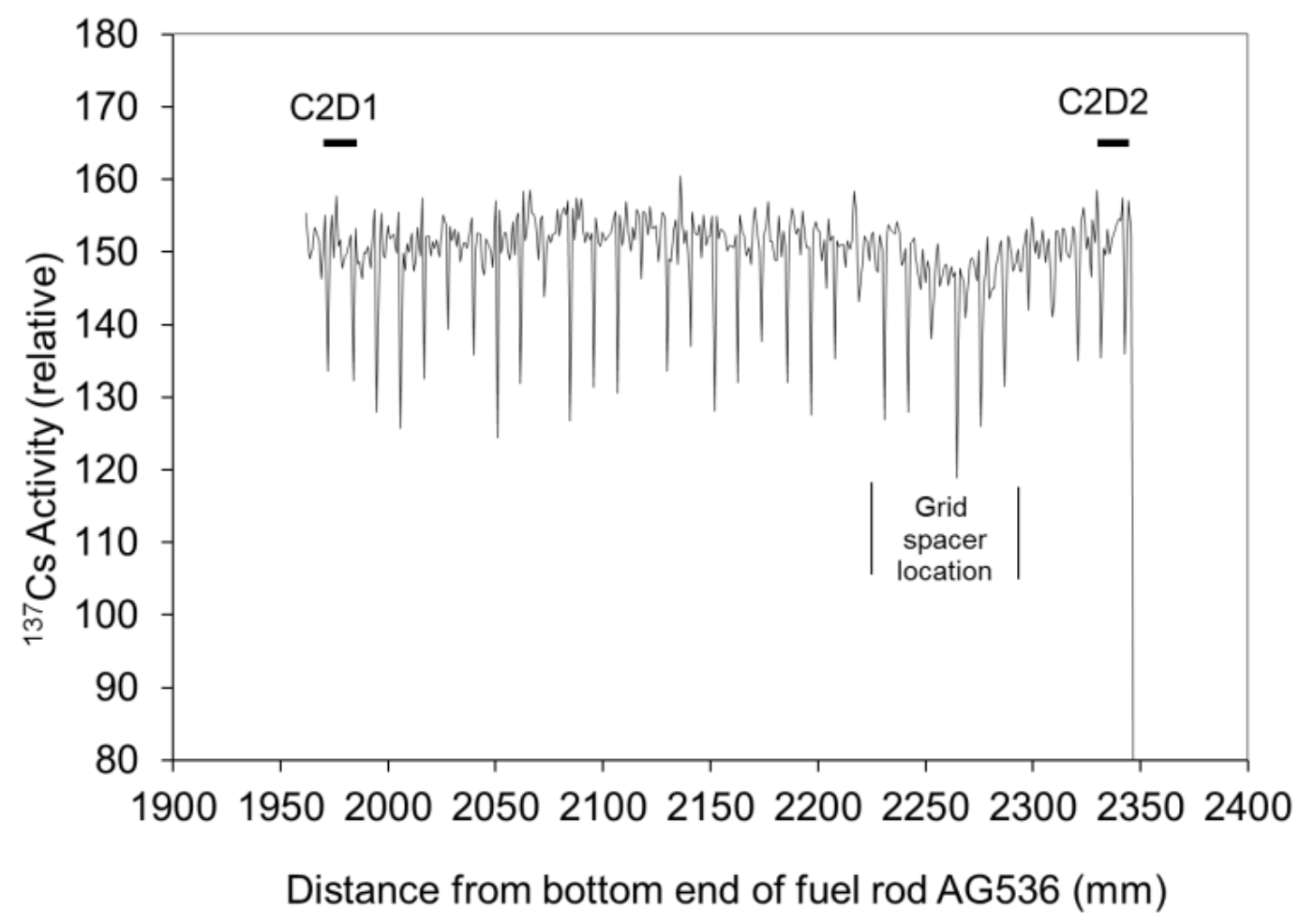


Figure 4

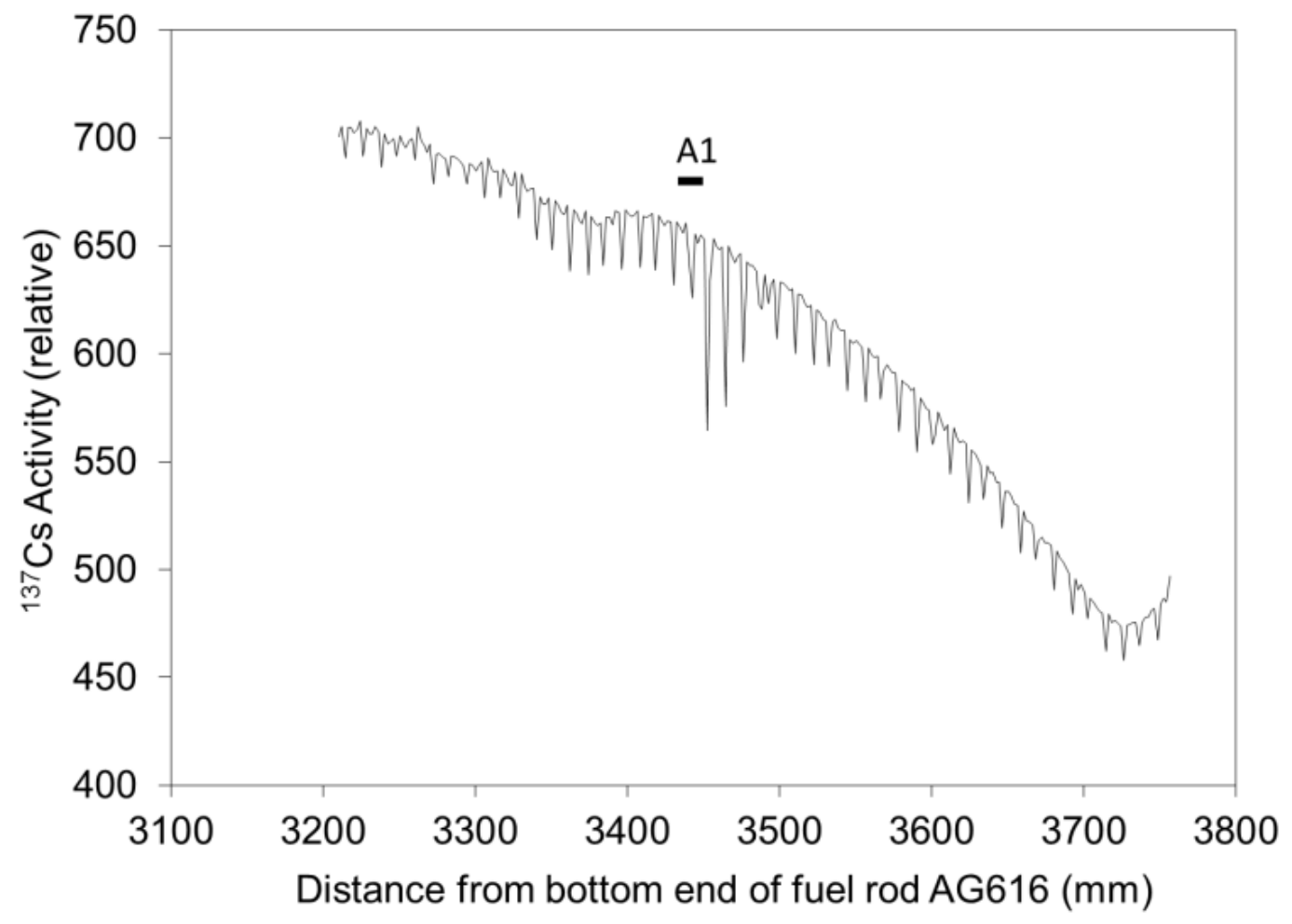


Figure 5

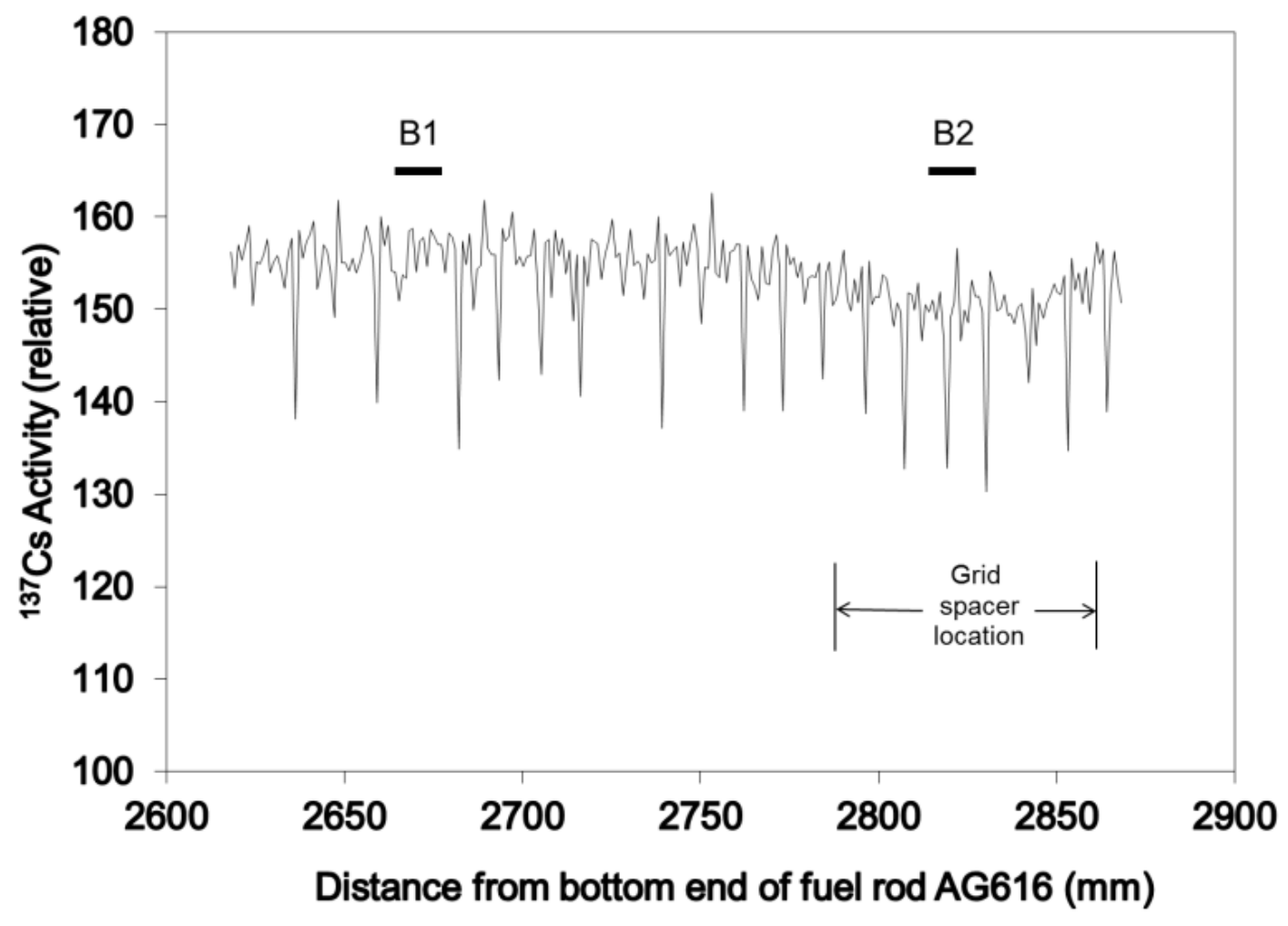


Figure 6

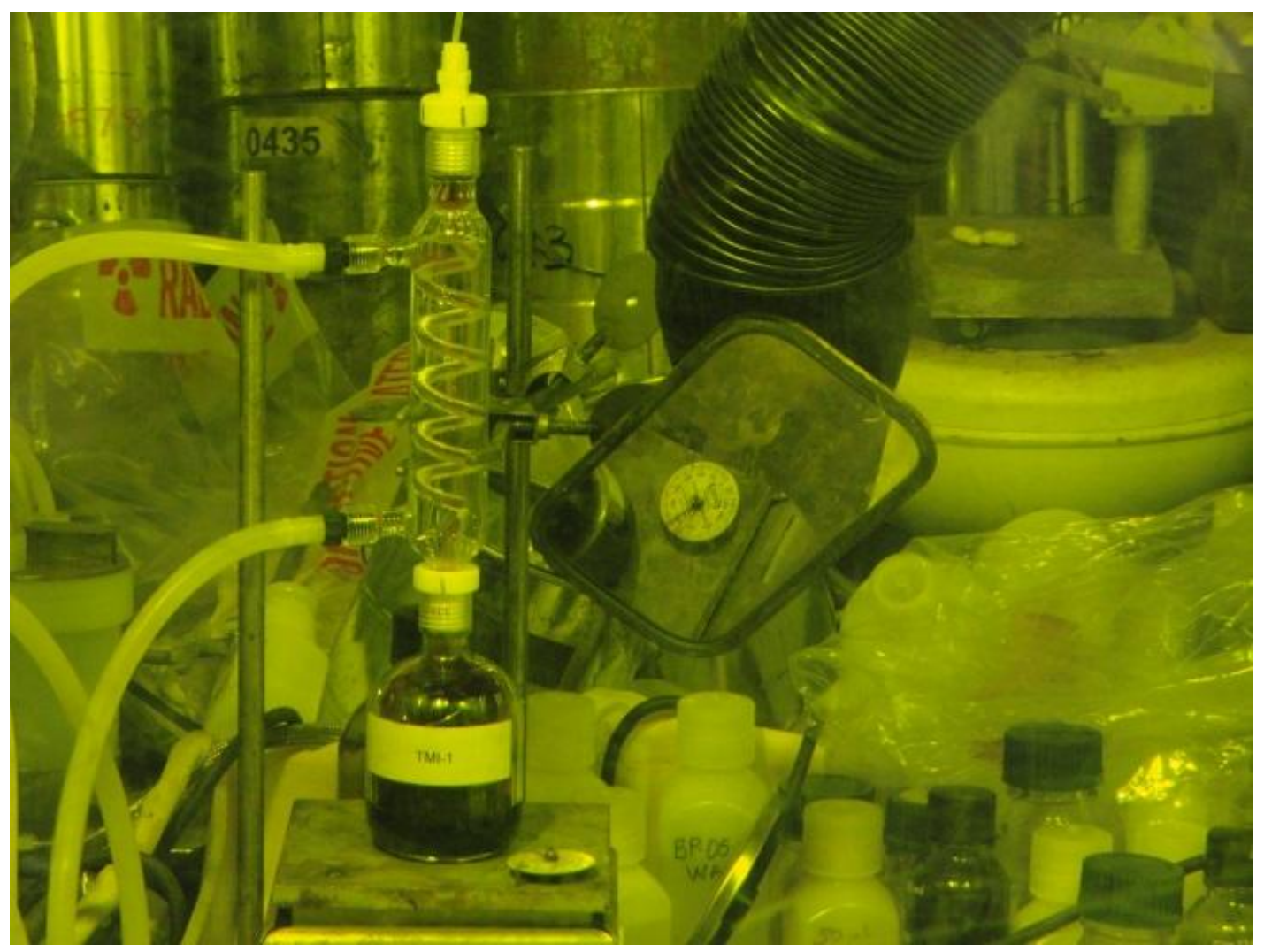


Figure 7

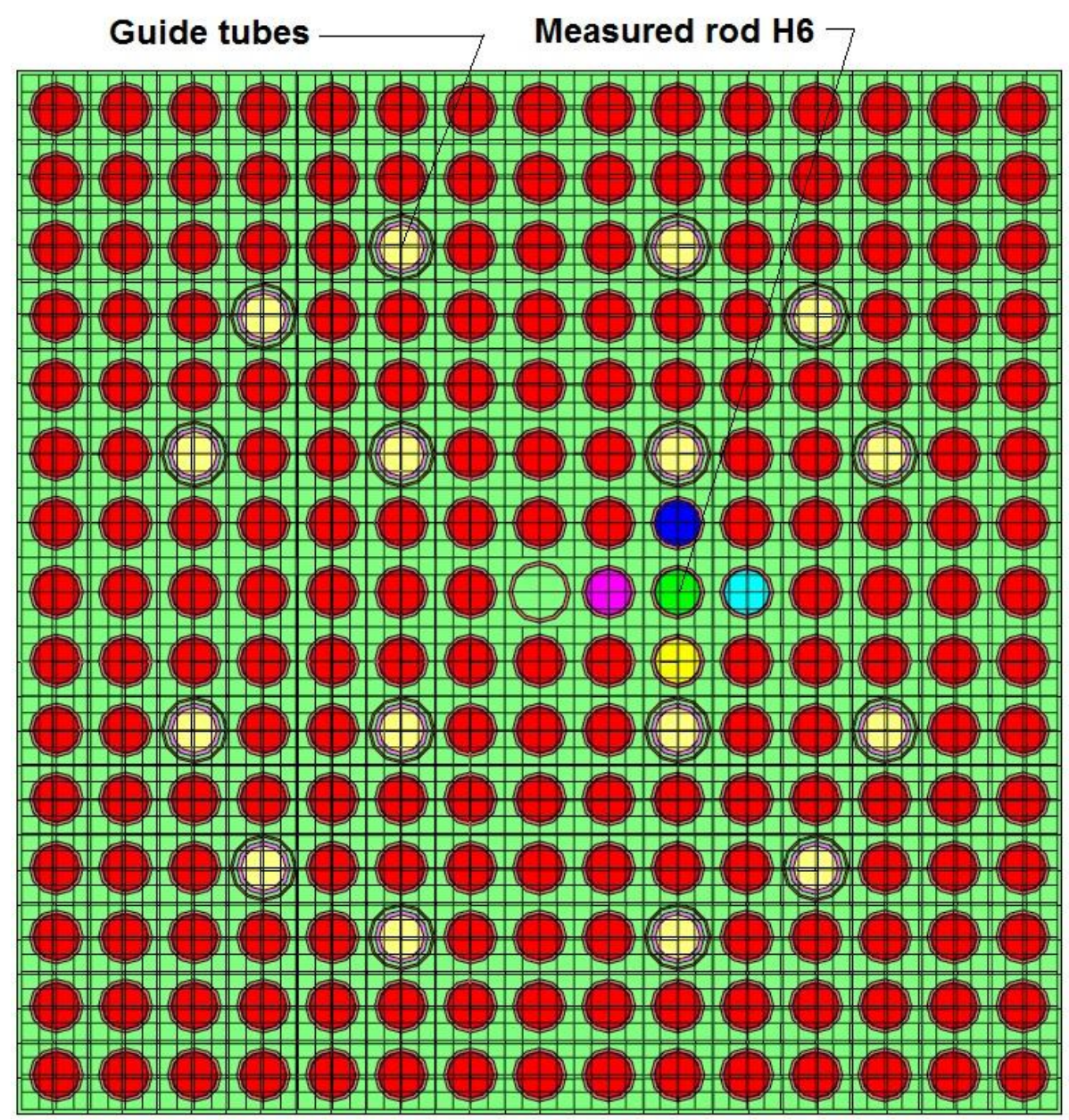


Figure 8

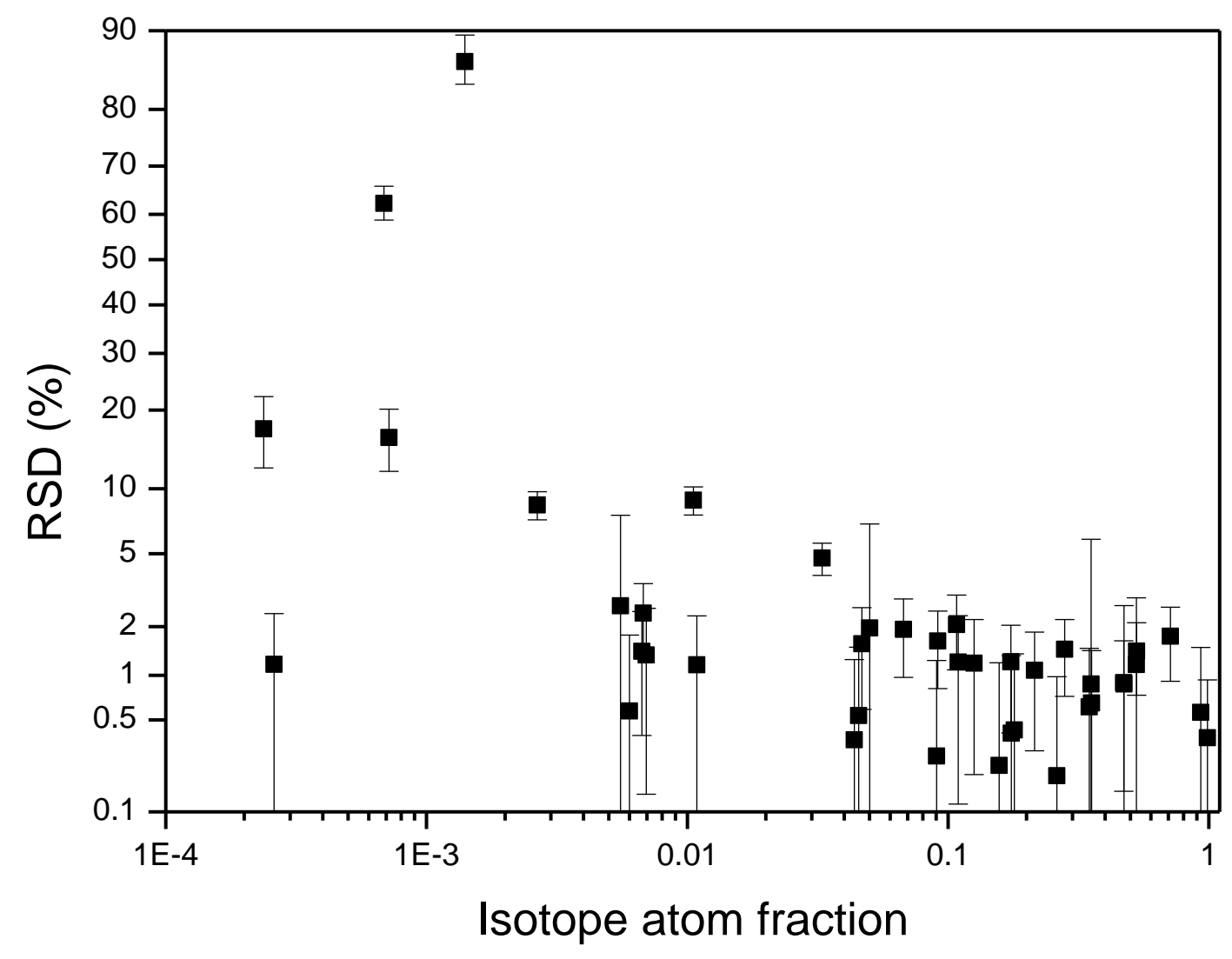


Figure 9

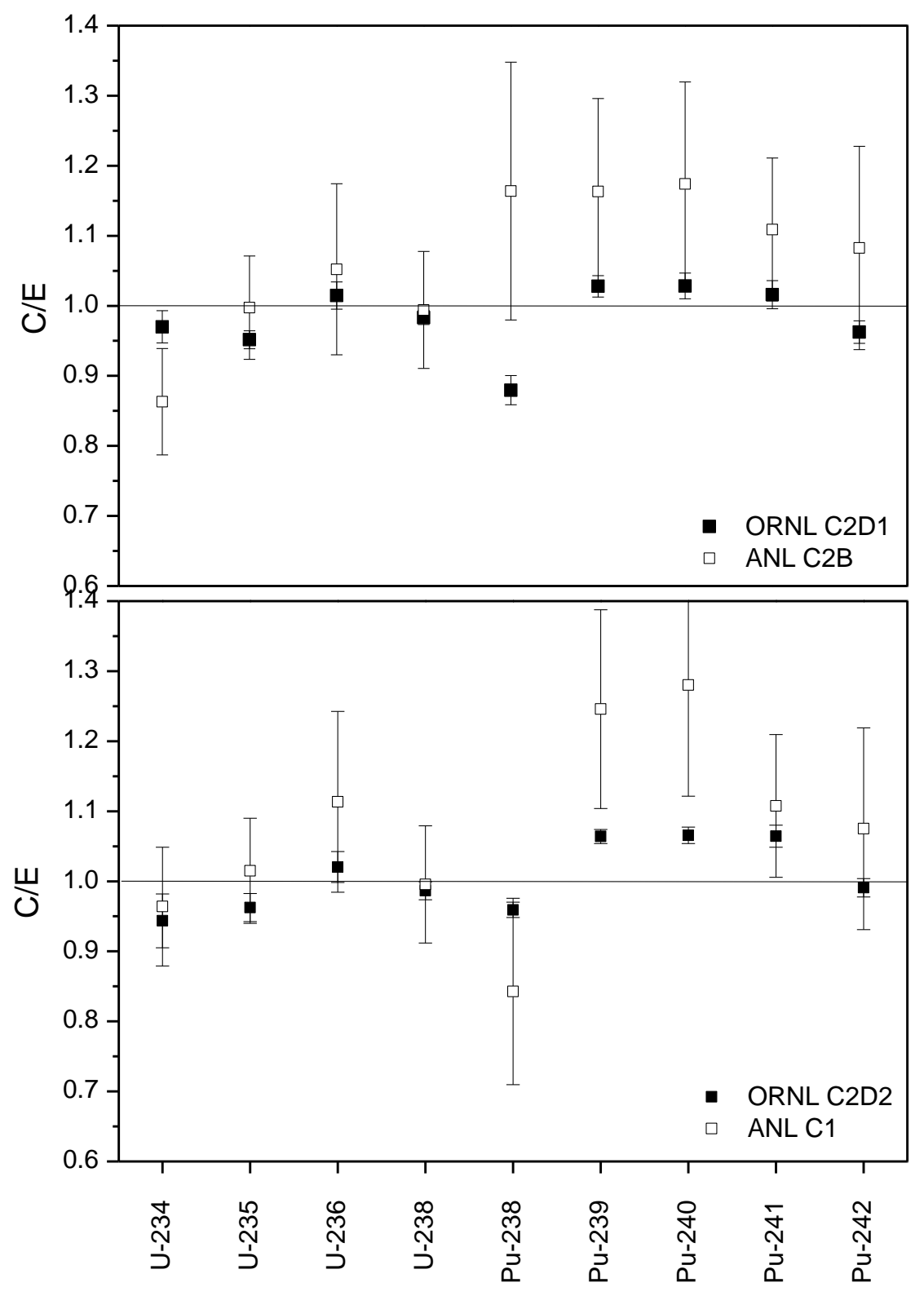


Figure 10
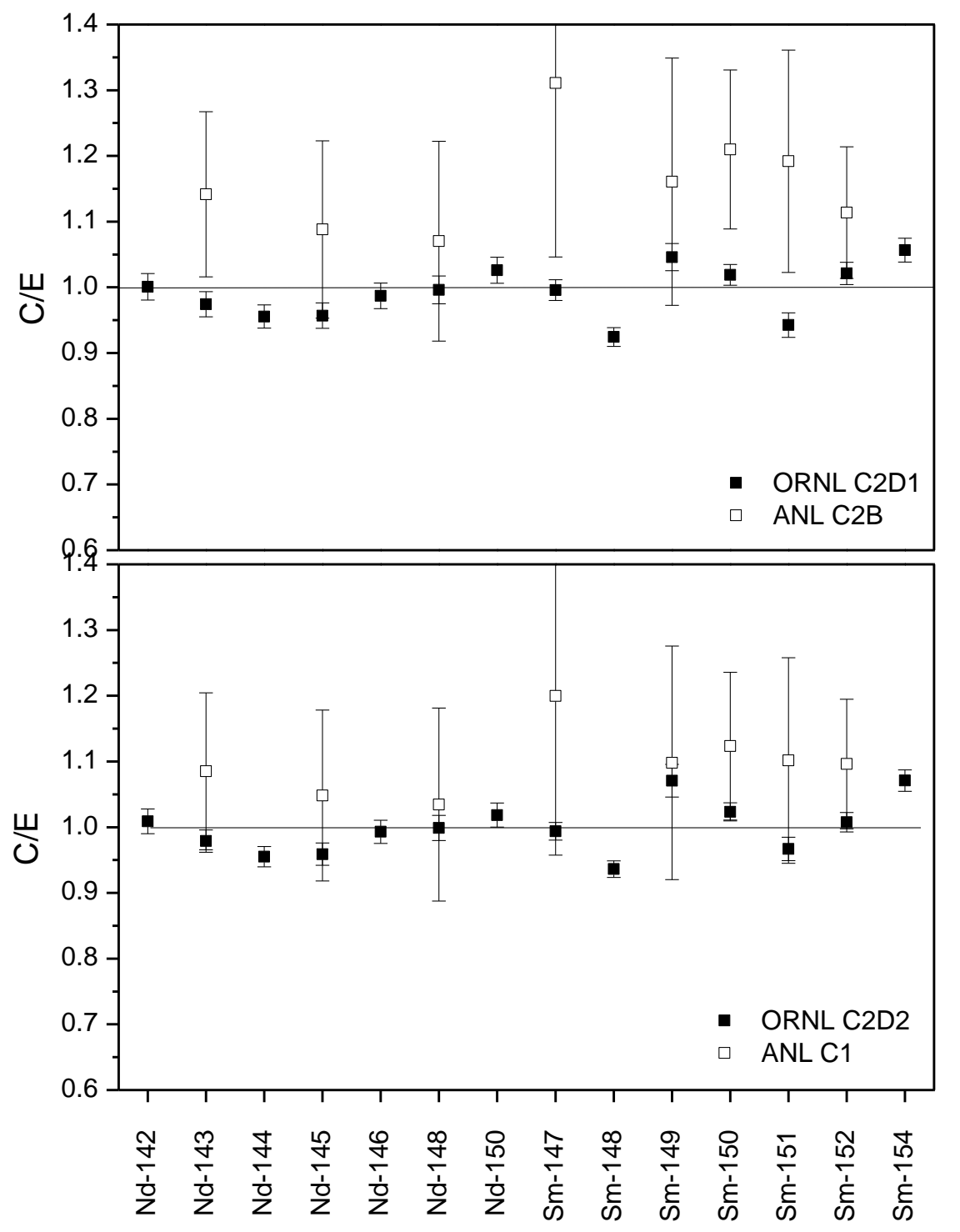
Figure 11

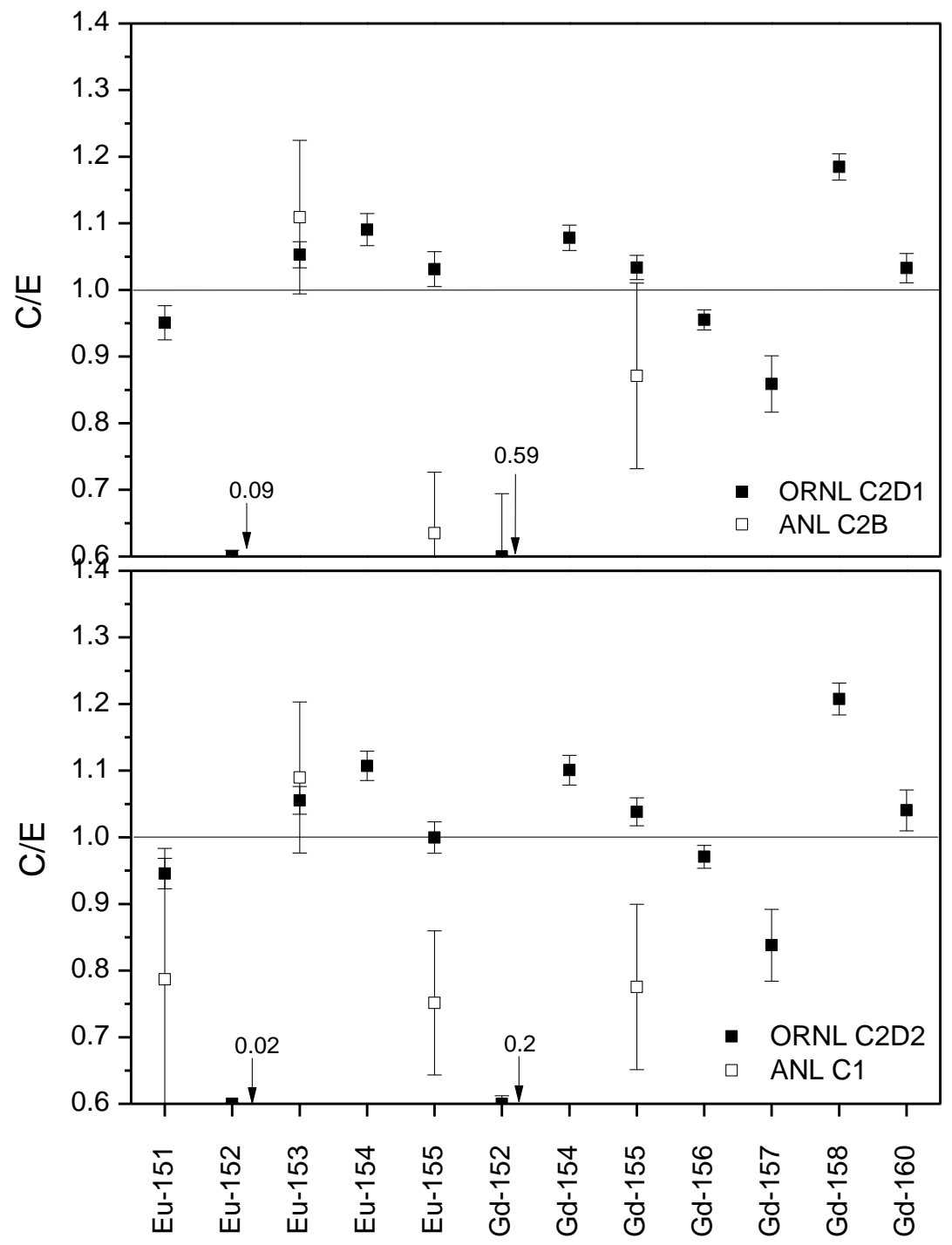


Figure 12

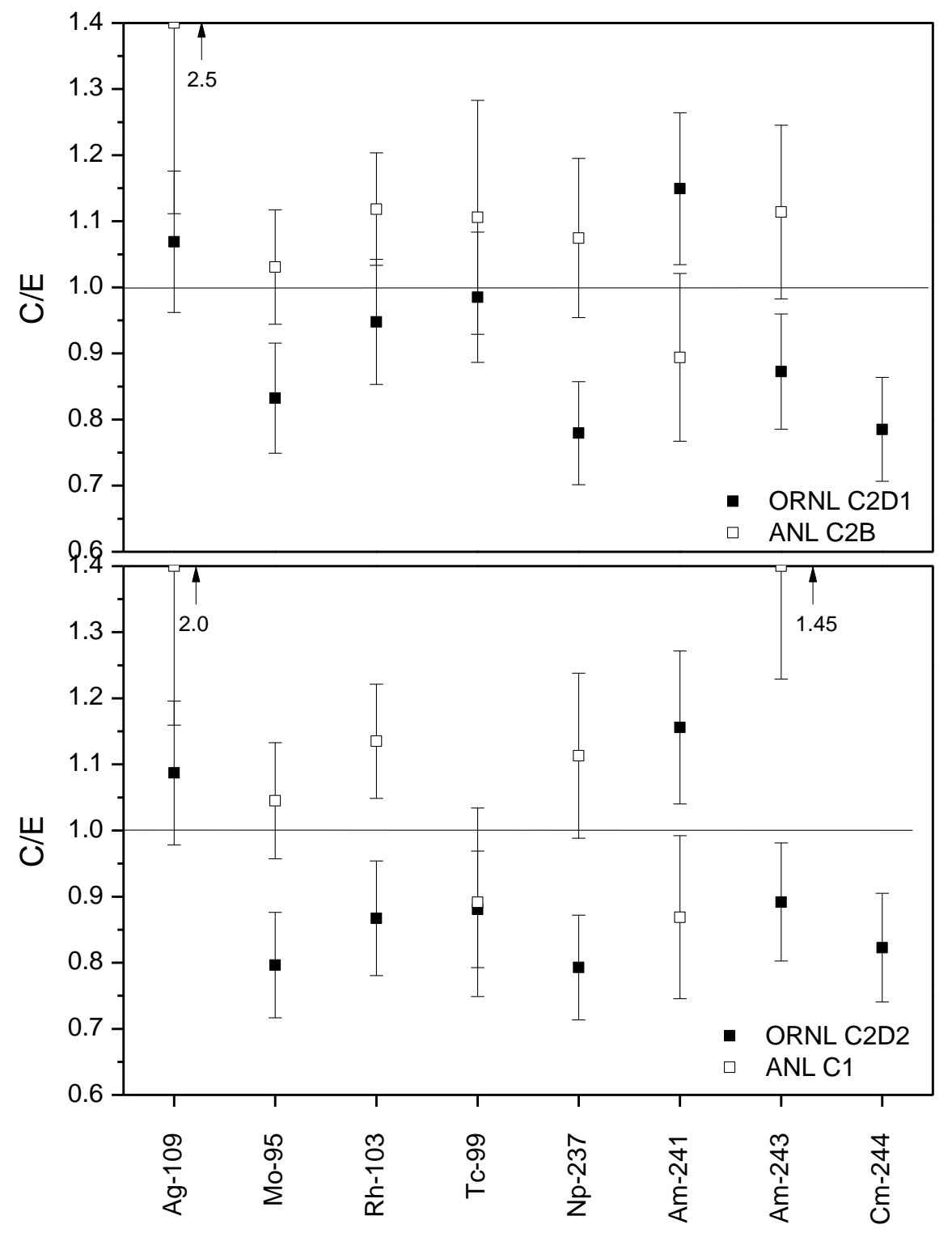

